\title{
CD44-mediated monocyte transmigration across Cryptococcus neoformans-infected brain microvascular endothelial cells is enhanced by HIV-1 gp41-190 ectodomain
}

Xiaolong He ${ }^{1 \dagger}$, Xiaolu Shi ${ }^{1+}$, Santhosh Puthiyakunnon ${ }^{1 \dagger}$, Like Zhang ${ }^{1}$, Qing Zeng ${ }^{1}$, Yan Li ${ }^{1}$, Swapna Boddu', Jiawen Qiu', Zhihao Lai ${ }^{2}$, Chao Ma², Yulong Xie², Min Long ${ }^{1}$, Lei Du', Sheng-He Huang ${ }^{1,3}$ and Hong Cao ${ }^{1 *}$

\begin{abstract}
Background: Cryptococcus neoformans ( $\mathrm{Cn}$ ) is an important opportunistic pathogen in the immunocompromised people, including AIDS patients, which leads to fatal cryptococcal meningitis with high mortality rate. Previous researches have shown that HIV-1 gp41-190 ectodomain can enhance $\mathrm{Cn}$ adhesion to and invasion of brain microvascular endothelial cell (BMEC), which constitutes the blood brain barrier (BBB). However, little is known about the role of HIV-1 gp41-190 in the monocyte transmigration across Cn-infected BBB. In the present study, we provide evidence that HIV-1 gp41-190 and Cn synergistically enhance monocytes transmigration across the $B B B$ in vitro and in vivo. The underlying mechanisms for this phenomenon require further study.

Methods: In this study, the enhancing role of HIV-1 gp41-190 in monocyte transmigration across Cn-infected BBB was demonstrated by performed transmigration assays in vitro and in vivo.

Results: Our results showed that the transmigration rate of monocytes are positively associated with $\mathrm{Cn}$ and/or HIV-1 gp41-190, the co-exposure (HIV-1 gp41-190 + Cn) group showed a higher THP-1 transmigration rate $(P<0.01)$. Using CD44 knock-down HBMEC or CD44 inhibitor Bikunin in the assay, the facilitation of transmigration rates of monocyte enhanced by HIV-1 gp41-190 was significantly suppressed. Western blotting analysis and biotin/avidin enzyme-linked immunosorbent assays (BA-ELISAs) showed that Cn and HIV-1 gp41-190 could increase the expression of CD44 and ICAM-1 on the HBMEC. Moreover, Cn and/or HIV-1 gp41-190 could also induce CD44 redistribution to the membrane lipid rafts. By establishing the mouse cryptococcal meningitis model, we found that HIV-1 gp41-190 and Cn could synergistically enhance the monocytes transmigration, increase the BBB permeability and injury in vivo.

Conclusions: Collectively, our findings suggested that HIV-1 gp41-190 ectodomain can enhance the transmigration of THP-1 through Cn-infected BBB, which may be mediated by CD44. This novel study enlightens the future prospects to elaborate the inflammatory responses induced by HIV-1 gp41-190 ectodomain and to effectively eliminate the opportunistic infections in AIDS patients.
\end{abstract}

Keywords: Cryptococcus neoformans, HIV-1 gp41-190 ectodomain, Blood-brain barrier, CD44

\footnotetext{
* Correspondence: gzhcao@smu.edu.cn

${ }^{\dagger}$ Equal contributors

'Department of Microbiology, Guangdong Provincial Key Laboratory of

Tropical Disease Research, School of Public Health and Tropical Medicine,

Southern Medical University, Guangzhou 510515, China

Full list of author information is available at the end of the article
} 


\section{Background}

Cryptococcus neoformans $(\mathrm{Cn})$ is an important pathogenic fungus with capsule and causes severe meningitis and disseminated infections, especially in patients with defective cellular immunity, such as AIDS patients [1, 2]. Cryptococcosis is the most common opportunistic fungal infection and one of the major causes of death in AIDS patients (mortality rate $\sim 30 \%$ ) [3, 4]. Despite major advances in the treatment of HIV-1 infection with Highly Active Antiretroviral Therapy (HAART), cryptococcosis remains prevalent even in developed countries [5-9]. Cn infects mainly through the respiratory tract, spreads from the pulmonary circulation to the brain tissues, resulting in meningitis $[10,11]$. The pathogenesis of cryptococcal meningitis (CM) is still largely unknown, while it is well known that crossing the BBB is the pivotal step leading to the development of meningitis. The damage of the BBB is generally induced by the interactions between pathogens and brain microvascular endothelial cells (BMECs), which leads to edema and increased permeability, and subsequently facilitate more interactions between the immune cells and BMECs [12]. Previous research had shown that $\mathrm{Cn}$ is able to cause considerable morphological changes and actin reorganization in HBMEC [1]. Many signaling molecules, including CD44, caveolin-1, PKC $\alpha$, endocytic kinase DYRK3, in lipid rafts have been characterized and shown to play an important role during the Cn internalization [2, 13-16].

Cryptococcosis is one of the most fatal co-morbidity factors of AIDS. The interrelationship between HIV-1 and $\mathrm{Cn}$ is intriguing and intricate, as both pathogens cause severe neuropathological complications. The details of how HIV-1 virotoxins, including gp120 and gp41, enhance $\mathrm{Cn}$ invasion of the $\mathrm{BBB}$ are still largely unknown. Our recent study has shown that HIV-1gp41-I90 has a remarkable effect in promoting the adhesion and invasion of $\mathrm{Cn}$ [17]. Through construction of a recombinant protein, HIV-1 gp41-I90, which is the ectodomain of gp41 (amino acid residues 579-611), we have shown that HIV-1 gp41-I90 ectodomain could activate many molecular events including up-regulation of ICAM- 1 on the HBMEC, redistribution of CD44 and $\beta$ actin on the lipid rafts and induction of membrane ruffling on the surface of HBMEC. These events could enhance brain invasion by $\mathrm{Cn}$ and eventually can lead to severe HIV-1-associated CM [17, 18]. CD44 is a cellsurface glycoprotein involved in cell-cell interactions, cell adhesion and migration, which is widely distributed in a variety of endothelial cells, including HBMEC [19]. The interaction between hyaluronic acid (HA) on the $\mathrm{Cn}$ and its receptor CD44 on the surface of HBMEC is the initial step in cryptococcal brain invasion [13]. The role played by $\mathrm{CD} 44 / \mathrm{HA}$ in the interaction between BMECs and leukocytes and the exudation of leukocyte is previously characterized [13]. CD44 has also been proposed to play an important role in $\mathrm{Cn}$ infection-induced adhesion and transmigration activities of leukocyte. It is reasonable to speculate that CD44 could also be important for HIV-1 gp41-190 ectodomain mediated brain invasion of $\mathrm{Cn}$.

Delineating the mechanism of $\mathrm{Cn}$ transmigration across the $\mathrm{BBB}$ is essential to explore the potential of HIV-1 in enhancing the brain invasion by $\mathrm{Cn}$. Many research groups have suggested three possible routes of $\mathrm{Cn}$ transmigration across the BBB: (1) Trans-cellular passage through endothelial cells by a specific ligand-receptor interaction $[1,20]$, this mode of invasion has been observed for Escherichia coli [21-23], group B Streptococcus [24], Listeria monocytogenes [25], Neisseria meningitides [26] and the fungal pathogen Candida albicans [27]; (2) Paracellular penetration after mechanical or biochemical disruption of the BBB [1, 28, 29], just like the protozoan Trypanosomasp [30, 31]; (3) “Trojan horse" method, in which the infected immune cells, such as monocytes carry the pathogen through the BBB, a method of infection by HIV-1 and simian immunodeficiency virus [32-34]. The existence of a Trojan horse method of crossing the BBB by $\mathrm{Cn}$ has been proved in a study by Caroline Charlier et al. [35]. Through infecting bone marrow-derived monocytes (BMDM) with $\mathrm{Cn}$ in vitro, the authors showed that fungal loads in brain of mice treated with $\mathrm{Cn}$-infected BMDM were much higher than the control group. Accumulating evidence shows that $\mathrm{Cn}$ can use multiple means of transmigration and disruption of the BBB.

Previous research had shown that HIV-1 infection is able to increase the monocyte capacity to migrate across the BBB [36]. As existence of a Trojan horse method of crossing the $\mathrm{BBB}$ by $\mathrm{Cn}$, it is reasonable to speculate that HIV-1 enhanced transmigration activity of monocytes might be responsible for severe brain disorder caused by $\mathrm{Cn}$. In present study, through performing transmigration assays, we found that $\mathrm{Cn}$ and HIV-1 gp41-I90 could synergistically enhance monocytes transmigration across the $\mathrm{BBB}$. Our findings provide a new idea for understanding the interrelationship between HIV-1 and Cn during the pathogenic progress of HIV-1-associated CM.

\section{Methods}

\section{Chemicals and reagent}

Evans blue (EB), L-(-)-Fucose, biotinylation kit and Caveolae/Rafts Isolation kit were purchased from Sigma-Aldrich (St. Louis, MO). Dynabeads M-450 Tosylactivated was purchased from Invitrogen (Carlsbad, CA). Ulex europaeus I (UEA I) lectin and mounting medium with DAPI were purchased from Vector (Buringame, CA). The HIV-1 gp41-I90 ectodomain peptide (gp41-I90) was prepared as previously described [37]. Recombinant HIV-1 Tat clade B protein and HIV-1 p24 recombinant were purchased from 
Prospec (Rehovort, Israel). All primary antibodies (Ab) were purchased from the commercial sources: a rabbit anti-MSFD2 Ab (sc-135305), a rabbit anti-CD44 Ab, a rat anti-Ly6C $\mathrm{Ab}$ and a rabbit anti-ICAM-1 Ab (Abcam, USA), a PE-conjugated anti-CD146 Ab (12-1469-41) and a PE-conjugated rat anti-mouse Ly6C Ab from eBiosciences (San Diego, CA, USA). The rest chemicals were obtained from Ding Guo Chang Sheng Company, Beijing, China.

\section{Fungi strains, cell lines and cultures}

$\mathrm{Cn}$ wild strains $\mathrm{B}-4500 \mathrm{FO} 2$ was a generous gift from A Jong (University of Southern California, Los Angeles, USA). Yeast cells were grown aerobically at $30{ }^{\circ} \mathrm{C}$ in $1 \%$ yeast extract, $2 \%$ peptone and $2 \%$ dextrose (YPD broth). Cells were harvested at early log phase, washed with phosphatebuffered saline (PBS) and resuspended. The yeast cell number was determined by direct counting from a hemocytometer [17]. Heat-inactivated $\mathrm{Cn}(\mathrm{H}-\mathrm{Cn})$ was obtained by heating the microorganisms three times at $121{ }^{\circ} \mathrm{C}$ for $15 \mathrm{~min}$ [38]. Only batches that showed no re-growth in YPD broth were employed. HBMEC were isolated and cultured as described previously [39-41], which were grown in RPMI 1640 medium supplemented with $10 \%$ heatinactivated fetal bovine serum, $10 \% \mathrm{Nu}$-serum, $2 \mathrm{mM}$ glutamine, $1 \mathrm{mM}$ sodium pyruvate, nonessential amino acids, vitamins, penicillin $\mathrm{G}(50 \mu \mathrm{g} / \mathrm{ml})$ and streptomycin $(100 \mu \mathrm{g} / \mathrm{ml})$ at $37{ }^{\circ} \mathrm{C}$ in $5 \% \mathrm{CO} 2$. Cells were detached by trypsin-EDTA and subcultured on collagen-coated Transwell ( $3 \mu \mathrm{m}$ pore size, $6.5-\mathrm{mm}$ diameter) (BD Biosciences, San Jose, CA, USA) from T-25 flasks when 70 \%-80 \% confluent. HBMEC monolayers on Transwell filters were monitored by measuring trans-endothelial electrical resistance (TEER) changes across the endothelial cell monolayer using an End Ohm epithelial voltohmeter (World Precision Instruments, Sarasota, FL, USA) [1, 27]. The cells are positive for factor VIII and fluorescently labeled acetylated low-density lipoprotein (Dil-AcLDL) uptake, demonstrating their endothelial origin and also express gamma glutamyl transpeptidase (GGT) and carbonic anhydrase (CA) IV, indicating their brain origin [42]. HBMEC are polarized and exhibit an average TEER value of $250-300 \Omega / \mathrm{cm}^{2}$ [1]. The cells also exhibit the typical characteristics for brain endothelial cells expressing tight junctions and maintaining apical-to-basal polarity. THP-1 cells were purchased from the cell bank of Chinese Academy of Sciences and grown in RPMI 1640 medium supplemented with $10 \%$ heat-inactivated fetal bovine serum, penicillin $\mathrm{G}(50 \mu \mathrm{g} / \mathrm{ml})$ and streptomycin $(100 \mu \mathrm{g} / \mathrm{ml})$ at $37{ }^{\circ} \mathrm{C}$ in $5 \% \mathrm{CO}_{2}$.

\section{Mice}

The C57BL/6 background mice (6 weeks of age) were brought from Animal Experimental Center of Southern Medical University (Guangzhou, China) and kept in the animal facility. They were raised in plastic cages and given food and water ad libitum. All experiments were approved by the ethics committee of Southern Medical University.

\section{CRISPR/Cas9-Mediated knockdown-CD44}

The CRISPR-Cas9 system was used in our study to mediate down-regulated expression of CD44 in HBMEC. Human CD44 cDNA sequence was obtained from Gen Bank (NM_000610) and two pairs of single guide RNA (sgRNA) sequences (named CD44-1 and CD44-2, as below) were designed online (http://www.e-crisp.org/ECRISP/designcrispr.html). The underlined sequences targeted the CD44 gene, and the bold italic letters indicate the BsmBI site. A 20 bp scrambled sequence (see below) was defined as a scramble control which was marked with "SC" in the text.

sgCD44-1:F:5'-CACCGCTACAGCATCTCTCGGACG G-3',

\section{R:3'-CGATGTCGTAGAGAGCCTGCCCAAA-5'} sgCD44-2:F:5'-CACCGGGCACTCACCGATCTGCGC C-3',

R: 3'-CCCGTGAGTGGCTAGACGCGGCAAA-5'

Scramble Control:F:5'-CACCGGCACTACCAGAGCT AACTCA-3,

\section{R:3'-CCGTGATGGTCTCGATTGAGTCA $\boldsymbol{A} \boldsymbol{A}-5$ '}

These sequences were annealed in $10 \times \mathrm{T} 4$ Ligation Buffer (NEB) withT4 PNK (NEB M0201S) by incubating oligonucleotides for $30 \mathrm{~min}$ at $37{ }^{\circ} \mathrm{C}, 5 \mathrm{~min}$ at $95{ }^{\circ} \mathrm{C}$ and ramping down to $25^{\circ} \mathrm{C}$ at $5{ }^{\circ} \mathrm{C} / \mathrm{min}$, followed by slow cooling to $4{ }^{\circ} \mathrm{C}$. The annealed DNA fragments were ligated into BsmBI sites of lentiCRISPRv2 (provided by Bao Zhang, Southern Medical University) to generate lentiCRISPRv2CD44-1, lentiCRISPRv2-CD44-2 and lentiCRISPRv2-SC plasmids, respectively. These plasmids were transfected into $293 \mathrm{~T}$ cells with lentiviral packaging vectors pCMVdR8.2 dvpr and pCMV-VSV-G (both provided by Bao Zhang, Southern Medical University) using lipofectamine 2000. Viruses were collected from the media $48 \mathrm{~h}$ posttransfection. HBMEC grown on 24 well plates were infected with collected viruses for $24 \mathrm{~h}$ in the presence of polybrene (Santa Cruz). Stably transfected clones were picked and maintained in medium containing $2 \mu \mathrm{g} / \mathrm{ml}$ puromycin for additional studies. Expression level of CD44 in stable cell line was analyzed by western blotting using anti-CD44 monoclonal antibodies. We assigned the stable cell line as KD-CD44 HBMEC in our study.

\section{THP-1 adhesion assay}

THP-1 adhesion assays were performed as described by Che et al. [43]. Briefly, confluent HBMEC monolayers on 24-well plates were stimulated with different concentrations of $\mathrm{Cn}\left(10^{5}-2 \times 10^{7} \mathrm{CFU} / \mathrm{ml}\right)$ or gp41-I90 $(0.02-20 \mu \mathrm{M})$ for $6 \mathrm{~h}$. For the time-course study, confluent HBMEC monolayers were stimulated at different time intervals $(0-24 \mathrm{~h})$ 
with a single dose of $\mathrm{Cn}\left(5 \times 10^{6} \mathrm{CFU} / \mathrm{ml}\right)$ or HIV-1 gp41I90 $(2 \mu \mathrm{M})$. After the incubation, monolayers were washed with PBS for four times. Each well was added with $1 \times 10^{6}$ THP-1 and incubated with $90 \mathrm{~min}$ at $37{ }^{\circ} \mathrm{C}$. Then, cells were washed for 5 times and fixed with $4 \%$ paraformaldehyde in PBS. Assays were performed in triplicate wells. Fifteen microscope fields were randomly selected from three wells for each treatment to count the number of adherent monocytes and the data were analyzed using analysis of variance (ANOVA).

\section{THP-1 transmigration assay}

THP-1 transmigration assays were performed as described previously $[44,45]$ with modification. HBMECs or KDCD44 HBMECs were cultured in trans-well filters $(3 \mu \mathrm{m}$ pore size, $6 \mathrm{~mm}$ diameter, Millipore). In order to exclude the possibility that the monocytes migration elicited was due to destruction of HBMEC, the integrity of the monolayer was inspected by TEER and microscopy before the start of the assay. For HBMEC stimulation, different doses of Cn or HIV-1 gp41-I90 were added to the upper chambers with $0.8 \mathrm{ml}$ EM (EM; containing 49 \% M199, 49 \% Ham's F12, $1 \mathrm{mM}$ sodium pyruvate and $2 \mathrm{mM}$ L-glutamine) for $6 \mathrm{~h}$. For the time-course study, HBMEC were stimulated at different time intervals $(0-24 \mathrm{~h})$ with a single dose of $\mathrm{Cn}\left(5 \times 10^{6} \mathrm{CFU} / \mathrm{ml}\right) \mathrm{Cn}$ or HIV-1 gp41-I90 $(2 \mu \mathrm{M})$. After stimulation, THP- $1\left(1 \times 10^{6}\right.$ cells in $0.2 \mathrm{ml}$ of EM) were added to the upper chamber and allowed to migrate over for $4 \mathrm{~h}$ (Dose response and kinetic assays were performed in advance to determine the optimized concentration and migration duration). At the end of the incubation, migrated THP-1 cells were collected from the lower chamber and counted in a blinded-fashion using a hemacytometer [43]. Final results of THP-1 transmigration were expressed as the percentage of THP-1 across the BMEC monolayers. For Bikunin treatment, BMEC were incubated with Bikunin (Gen-Script Corp., catalog no. 300233) in both upper and lower chambers for $1 \mathrm{~h}$ before stimulation [16]. The pre-treating time of bikunin was determined according to kinetic assays. The Bikunin was present throughout the monocytes transmigration experiment until the end.

\section{Assays of surface expression of CD44 and ICAM- 1}

As ICAM-1 and CD44 play a role in the leukocyte transmigration process during inflammatory, we next performed BA-ELISAs to measured the expression of CD44 and ICAM-1 on HBMEC. Before the assays, ICAM-1 and CD44 antibody were biotinylated with biotin using a biotinylation kit as described by the manufacturer. The methods for ELISAs were similar to those described previously [43]. HBMEC monolayers which grown on Transwell were treated with $\mathrm{Cn}\left(5 \times 10^{6} \mathrm{CFU} / \mathrm{ml}\right)$ and HIV-1 gp41-I90 $(2 \mu \mathrm{M})$ alone or joint use of them and incubated for $6 \mathrm{~h}$. Treated monolayers were washed three times with PBS, fixed with $4 \%$ paraformaldehyde and blocked for 30 min with PBS containing $5 \%$ BSA. Biotin conjugated ICAM-1 antibody or CD44 antibody were added immediately after the blocking step. Incubation was carried out for $1 \mathrm{~h}$ at $37^{\circ} \mathrm{C}$. Cells were washed five times with PBS added $1 \% \mathrm{BSA}$ and incubated with peroxidase-conjugated avidin for $45 \mathrm{~min}$ at $37{ }^{\circ} \mathrm{C}$. After the avidin incubation, cells were washed five times and liquid TMB substrate was added. The liquid was transferred to an ELISA plate after $15 \mathrm{~min}$. Equal volume stop solution was added, and optical density at $450 \mathrm{~nm}$ was read. For each ELISA, an isotype-matched control antibody was used in place of the primary antibody in three wells, and this background was subtracted from the signal.

\section{Preparation of membrane lipid rafts from HBMECs}

Lipid rafts were extracted using Caveolae/Rafts Isolation kit as described previously [13]. For each sample, HBMECs were grown in a 6 well plates for 2 days. On the day of the experiment, the cells were individually incubated with either PBS (control), or $2 \mu \mathrm{M}$ HIV-1 gp41-I90, or $5 \times 10^{6} \mathrm{CFU} / \mathrm{ml} \mathrm{Cn}$ or $5 \times 10^{6} \mathrm{CFU} / \mathrm{ml} \mathrm{Cn}+2 \mu \mathrm{M}$ HIV-1 gp41-I90 individually for $6 \mathrm{~h}$ in the experimental medium. After incubation, the cells were washed with PBS three times, scraped in PBS and spun down at $750 \mathrm{~g}$ at $4{ }^{\circ} \mathrm{C}$. Cell pellets were lysed in $200 \mu \mathrm{l}$ of TN solution [25 mM Tris/HCl (pH 7.5), 1 mM DTT (dithiothreitol), a cocktail of protease inhibitors, $10 \%$ sucrose and $1 \%$ Triton X-100] on ice, and incubated for $30 \mathrm{~min}$ on ice. Samples were mixed with $1.16 \mathrm{ml}$ of ice-cold OptiPrep ${ }^{\mathrm{TM}}$, transferred into SW40 centrifuge tubes and overlaid with $2 \mathrm{ml}$ each of 30,30, 25, 20 and $0 \%$ OptiPrep $^{\mathrm{TM}}$ in TN buffer. The gradients were spun at 35000 r.p.m. in an $\mathrm{SW} 40$ rotor for $5 \mathrm{~h}$ at $4{ }^{\circ} \mathrm{C}$. Nine fractions were collected from the top to the bottom of centrifuge tubes. For western blotting, equal amounts of proteins from each fraction were used. Rabbit anti-CD44 Ab (Abcam, 1:5000 dilution) and anti-rabbit-HRP conjugate (1:500 dilution) were used in these experiments.

\section{Western blotting analysis}

To assess Cn or HIV-1 gp41-I90 induced expression of CD44 and ICAM-1 on HBMEC, monolayers was subjected to individual treatment with PBS, $5 \times 10^{6} \mathrm{CFU} / \mathrm{ml}$ Cn, $2 \mu \mathrm{M}$ HIV-1 gp41-I90, $5 \times 10^{6} \mathrm{CFU} / \mathrm{ml} \mathrm{Cn}+2 \mu \mathrm{M}$ HIV-1 gp41-I90 or 0, 0.2, 2 and $20 \mu \mathrm{M}$ HIV-1 gp41-I90 respectively for $6 \mathrm{~h}$ at $37{ }^{\circ} \mathrm{C}$ in $5 \% \mathrm{CO}_{2}$. After incubation, the cells were collected and lysed on ice in lysis buffer [ $1 \times \mathrm{PBS}, 1 \% \mathrm{NP} 40,0.1 \%$ sodium dodecyl sulphate, $5 \mathrm{mM}$ ethylenediaminetetraacetic acid (EDTA), $0.5 \%$ sodium deoxycholate, $1 \mathrm{mM}$ sodium orthovanadate] with protease inhibitors. The protein concentration was measured using the Bradford protein assay (Beyotime Institute 
of Biotechnology, Shanghai, China). Equal amounts of proteins were separated electrophoretically and transferred onto polyvinylidene difluoride membranes (Millipore). Each membrane was probed with a rabbit anti-CD44 antibody (1:5000) or rabbit anti-ICAM-1antibody (1:200). Expression of protein was examined with a horseradish peroxidaseconjugated anti-rabbit IgG and enhanced chemiluminescence (Pierce, Rockford, IL, USA). A goat polyclonal anti- $\beta$-actin antibody (1:1500; Santa Cruz Biotechnology) was used to confirm equal loading of proteins. The intensity of the bands was scanned and analyzed with Alpha Imager gel documentation system and analysis software.

\section{Mouse cryptococcal meningitis model}

All the animal experiments were performed strictly according to the guidelines for animal care in Southern Medical University (China). Our protocols were approved (Approval No. 2014A016) by the School of Public Health and Tropical Medicine of Southern Medical University, which obtained the permission for performing the research protocols and all animal experiments conducted during the present study from the ethics committee of Southern Medical University. All surgery was performed under anesthesia with ketamine and lidocaine, and all efforts were made to minimize suffering. For study the role of HIV-1 gp41-I90 on Cn-caused monocyte recruitment into the CNS of mice, mouse cryptococcal meningitis model was established as described previously [17]. 6 weeks-old C57BL/6 mice (6 mice each group) were intravenously injected with $10^{6} \mathrm{Cn}$ cells via the tail vein, with or without HIV-1 gp41-I90 (10 $\mu \mathrm{g} / \mathrm{g}$ mouse weight). After $24 \mathrm{~h}$ injection, mice were anaesthetized with ketamine and lidocaine, and blood samples were collected from heart puncture for isolation and purification of mouse brain microvascular endothelial cells. After perfusion from heart puncture with $20 \mathrm{ml}$ PBS, the skull was opened. CSF samples were collected by washing the brain tissues with $100 \mu \mathrm{l}$ of PBS, and then by washing the cerebral ventricles and cranial cavity with another $100 \mu \mathrm{l}$ of PBS. CSF samples containing more than 10 erythrocytes per $\mu \mathrm{l}$ were discarded as contaminated samples. As the expression level of CD14 is very low in mouse monocytes, anti-Ly6C $\mathrm{Ab}$ was used to determine monocyte in CSF [46]. Monocytes were stained with a PE-conjugated rat anti-mouse Ly6C Ab (eBiosciences, CA, USA) and counted under the fluorescence microscope.

\section{Isolation and purification of mouse brain microvascular endothelial cells}

Recently, we have demonstrated that circulating BMECs (cBMECs) can be used as potential novel cell-based biomarkers for indexing of the BBB injury [47]. This technology was used by us to explore whether HIV-1 gp41-I90 is able to increase $\mathrm{Cn}$-associated BBB damages in our study. Briefly, beads were prepared according to the manufacturer's instructions (Invitrogen) and resuspended in Hanks' balanced salt solution (HBSS, Invitrogen Corp., Carlsbad, CA, USA) plus $5 \%$ fetal calf serum (HBSS $+5 \%$ FCS) to a final concentration of $4 \times$ $10^{8}$ beads $/ \mathrm{ml}$. The cBMECs were prepared as described previously [47, 48]. Endothelial cells from blood samples were isolated by absorption to Ulex-coated beads [49] and detached from the beads by fucose. Detached endothelial cells were adhered again to MFSD2a-coated beads. To counting the cBMECs from blood samples, cells adhered to MFSD2a-coated beads were labeled with PE-conjugated CD146 antibody and transferred to glass splices by cytospin for counting under a fluorescence microscope. These endothelial cells were positive for CD146 [47], demonstrating their endothelial origin, and also expressed MFSD2a [50], indicating their brain origin. Total cBMECs were identified based on their CD146 (endothelial cell marker) ${ }^{+} /$DAPI (nuclei) ${ }^{+}$phenotypes.

\section{Histopathology and immunohistochemistry}

Mouse brain tissue was fixed in $4 \%$ phosphate-buffered paraformaldehyde and was paraffin-embedded. Immunohistochemistry was performed on $5 \mu \mathrm{m}$ paraffin tissue sections. Mouse monocytes were identified with antiLy6C (1:100; Abcam). To detect primary Abs, a goat anti-rabbit antibody conjugated with horseradish peroxidase was used with $50 \mathrm{mM}$ Tris $\cdot \mathrm{HCl}$ buffer ( $\mathrm{pH}$ 7.4) containing $\mathrm{DAB}$ and $\mathrm{H}_{2} \mathrm{O}_{2}$, and the sections were lightly counterstained with hemotoxylin.

\section{Statistical analysis}

Data are shown in mean \pm standard deviation and analyzed by one-way ANOVA tests. All statistical analysis was carried out at $5 \%$ level of significance and $P$ value less than 0.05 was considered to be significant. SPSS software (version 13.0) was used for statistical analysis. The synergistic enhancing effect on joint use of $\mathrm{Cn}$ and HIV-1 gp41-I90 was analyzed using the CalcuSyn Software (Biosoft).

\section{Results}

Effect of Cn and HIV-1 gp41-I90 on adhesion and transmigration of THP-1

Recruitment of monocytes into CNS plays an important role in the inflammatory response induced by fungal factors [51]. To determine the role of Cn and HIV-1 gp41-I90 on transmigration of monocytes, we first evaluated the effect of $\mathrm{Cn}$ and HIV-1 gp41-I90 on monocytes adhesion to HBMEC at different yeast doses $\left(10^{6}-2 \times 10^{7} \mathrm{CFU} / \mathrm{ml}\right)$ and time intervals $(0-24 \mathrm{~h})$. Individually, as shown in Fig. 1a-d, $\mathrm{Cn}$ and gp41-190 not only could dose-dependently induce adhesion of monocytes to HBMEC, but also it is timedependent. Next, we performed transmigration assays to 

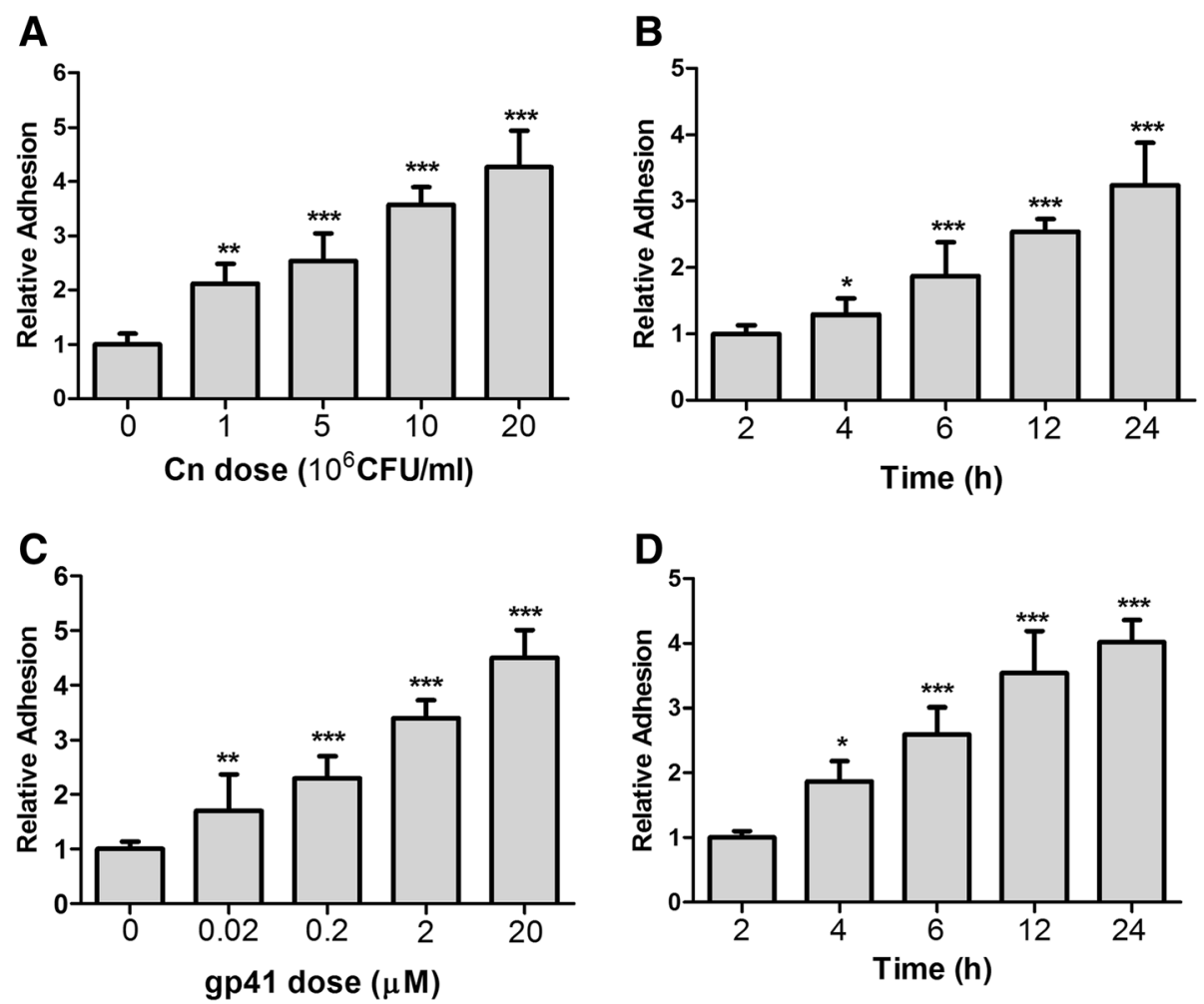

Fig. $1 \mathrm{Cn}$ and HIV-1 gp41-190 induce THP-1 adhesion to HBMEC monolayers in a dose- and time-dependent manner. THP-1 adhesion assays were performed as described in the Methods section. a, $\mathbf{c}$ Induction of THP-1 adhesion with different doses $\left(10^{6}-2 \times 10^{7} \mathrm{CFU} / \mathrm{ml}\right)$ of Cn and HIV-1 gp41 $(0-20 \mu \mathrm{M})$. b, d Time-course study of $\mathrm{Cn}$ and HIV-1 gp41-190-induced THP-1 adhesion to HBMEC monolayers. THP-1 adhesion was triggered by $5 \times$ $10^{6} \mathrm{CFU} / \mathrm{ml}$ of $\mathrm{Cn}$ or $2 \mu \mathrm{M}$ HIV-1 gp41-190. Adhesion was expressed as an $\mathrm{n}$-fold increase relative to the basal level. ${ }^{*} P<0.05,{ }^{* *} P<0.01,{ }^{* * *} P<0.001$

test whether Cn and HIV-1 gp41-I90 could induce monocytes transmigration across the BBB in vitro at a manner similar to adhesion. As we expected, Cn and HIV-1 gp41I90 could also induce monocytes transmigration across the $\mathrm{BBB}$ in vitro in a dose- and time-dependent manner (Fig. 2a-d). In order to exclude the possibility that the increased transendothelial migration by $\mathrm{Cn}$ or HIV-1 gp41I90 was due to disruption of the BBB, the integrity of the monolayer was inspected by determining the TEER across the monolayer. As shown in Fig. 5c, the TEER only declined to $<8 \%$ of the starting value after incubation with indicated doses of $\mathrm{Cn}$ and HIV-1 gp41-I90 or joint use of them. These results suggest that $\mathrm{Cn}$ and gp41-190 could induce monocyte adhesion to and transmigration across the HBMEC monolayers.

HIV-1 gp41-190 and Cn synergistically enhance the adhesion and transmigration activity of monocytes

In this assay, the adhesion rate of THP-1 was measured in four groups: PBS, Cn, HIV-1 gp41-I90 and joint use of Cn and HIV-1 gp41-I90 (Fig. 3a). Compared with the control group, all other groups showed significant increase in the adhesion rates, among which the HIV-1 gp41-I90 + Cn group was the highest. For the time-course study of THP-
1 transmigration, as shown in Fig. 3b, when the incubation time was increased to $24 \mathrm{~h}$, the transmigration rate of HIV-1 gp41-I90 + Cn group increased to $32 \%$ compared to the Cn group (19.2\%) and HIV-1 gp41-I90 group (21.8\%). Therefore, we concluded that the co-exposure of HIV-1 gp41-I90 and Cn in HBMEC has a significant time effect in transmigration of THP-1 cells. Moreover, the coexposure group showed a higher rate initially, and the pro-migration effect was more durable as well. Determination of a synergistic effect of $\mathrm{Cn}$ and HIV-1 gp41-I90 combination was performed according to the median effect principle using the CalcuSyn Software (Biosoft) as described previously [52]. The CI values for the combination treatment of $\mathrm{Cn}$ and HIV-1 gp41-I90 were less than 1, suggesting that the combination is highly synergistic. These results suggested that HIV-1 gp41-I90 and Cn was able to synergistically enhance the adhesion and transmigration activity of monocytes.

\section{Specificity of synergistically enhanced transmigration activity of monocyte by $\mathrm{Cn}$ and HIV-1 gp41}

In Fig. 2, we showed evidence of a dose- and timedependent increase in monocyte transmigration activity following BMEC treatment with $\mathrm{Cn}$ and HIV-1 gp41. 

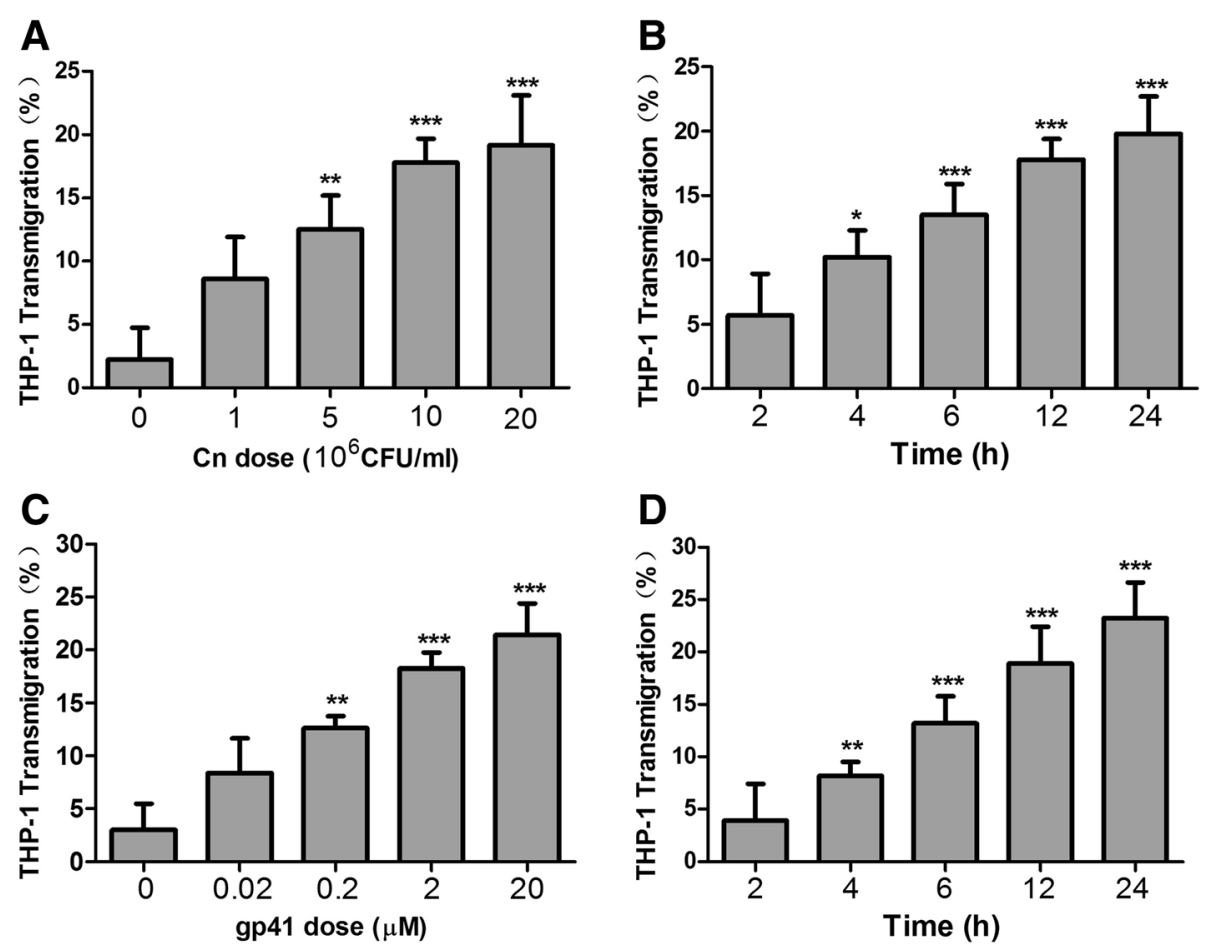

Fig. $2 \mathrm{Cn}$ and HIV-1 gp41-190 induce THP-1 transmigration across HBMEC monolayers in a dose- and time-dependent manner. a, $\mathbf{c}$ Different doses $\left(10^{6}-2 \times 10^{7} \mathrm{CFU} / \mathrm{ml}\right)$ of $\mathrm{Cn}$ and HIV-1 gp41-190 (0-20 $\mathrm{\mu M}$ ) induced THP-1 transmigration. b, d Time-course study of $\mathrm{Cn}$ and HIV-1 gp41-190-induced THP-1 transmigration across HBMEC monolayers. THP- 1 transmigration was triggered by $5 \times 10^{6} \mathrm{CFU} / \mathrm{ml}$ of $\mathrm{Cn}$ or $2 \mu \mathrm{M}$ HIV-1 gp $41-190$. The values represent the mean percent transmigrating THP-1 of triplicate samples and are representative of one experiment from three independent experiments showing similar data. ${ }^{*} P<0.05,{ }^{*} P<0.01,{ }^{* *} P<0.001$ compared with control

However, it is not clear whether these enhancing effects are specific to $\mathrm{Cn}$ and gp41. In order to further investigate this issue, heat-inactivated Cn, HIV Tat and p24 were used in transmigration assays. Briefly, HBMECs cultured in trans-well filters were treated with either PBS (control), $\mathrm{Cn}\left(1 \times 10^{6} \mathrm{CFU} / \mathrm{ml}\right), \mathrm{H}-\mathrm{Cn}\left(1 \times 10^{6} \mathrm{CFU} / \mathrm{ml}\right), \mathrm{HIV}-1$ gp41 $(0.2 \mu \mathrm{M})$, HIV Tat $(0.2 \mu \mathrm{M})$ or HIV p24 $(0.2 \mu \mathrm{M})$ for $6 \mathrm{~h}$. THP-1 transmigration assays were performed as described as Methods section. Like Cn and HIV-1 gp41, as shown in Fig. 4a, H-Cn and HIV Tat could also increase monocytes transmigration across BBB. Among these stimulations, the HIV Tat molecule contributes a higher enhancement of monocytes transmigration across to BBB. Next, we performed transmigration assays again to further examine whether H-Cn and HIV-1 gp41 or Cn and HIV Tat could also synergistically enhance the transmigration
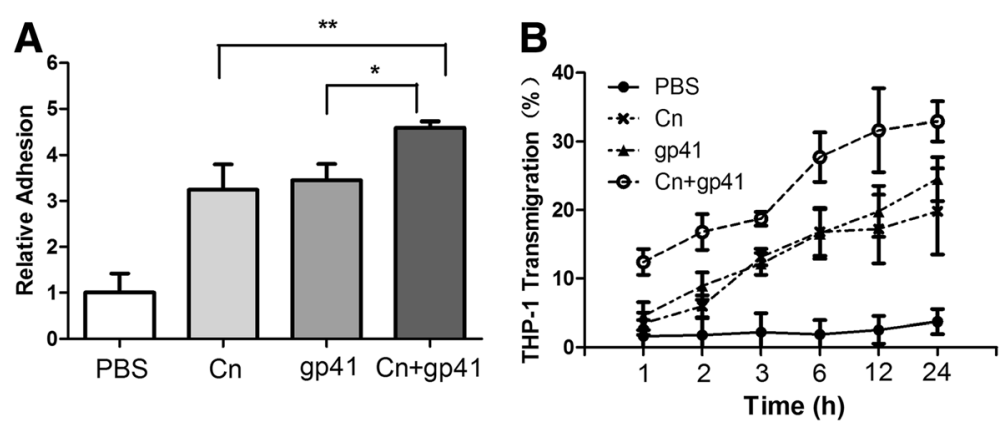

Fig. $3 \mathrm{Cn}$ and HIV-1 gp41-190 co-induced adhesion and transmigration of THP-1 to HBMEC. a Induction of THP-1 adhesion with Cn and HIV-1 gp41 alone or $\mathrm{Cn}$ in combination with HIV-1 gp41. The adhesion of THP-1 was triggered by $5 \times 10^{6} \mathrm{CFU} / \mathrm{ml}$ of $\mathrm{Cn}, 2 \mu \mathrm{M}$ of HIV-1 gp41-190 or both of them. Joint use of $\mathrm{Cn}$ and HIV-1 gp41-190 significantly induced THP-1 adhesion at $1.5 \mathrm{~h}$ after addition of THP-1 to the monolayer when compared with use $\mathrm{Cn}$ and HIV-1 gp41 alone. b Time-course study of $\mathrm{Cn}$ and HIV-1 gp41-190 induced THP-1 transmigration across HBMEC monolayers. THP-1 transmigration was triggered by $5 \times 10^{6} \mathrm{CFU} / \mathrm{ml} \mathrm{Cn}, 2 \mu \mathrm{M}$ HIV-1 gp41-190 or both of them. The values represent the mean of triplicate samples and are representative of one experiment from three independent experiments showing similar data. ${ }^{*} P<0.05$, $\left.{ }^{* *} P<0.01\right)$ 

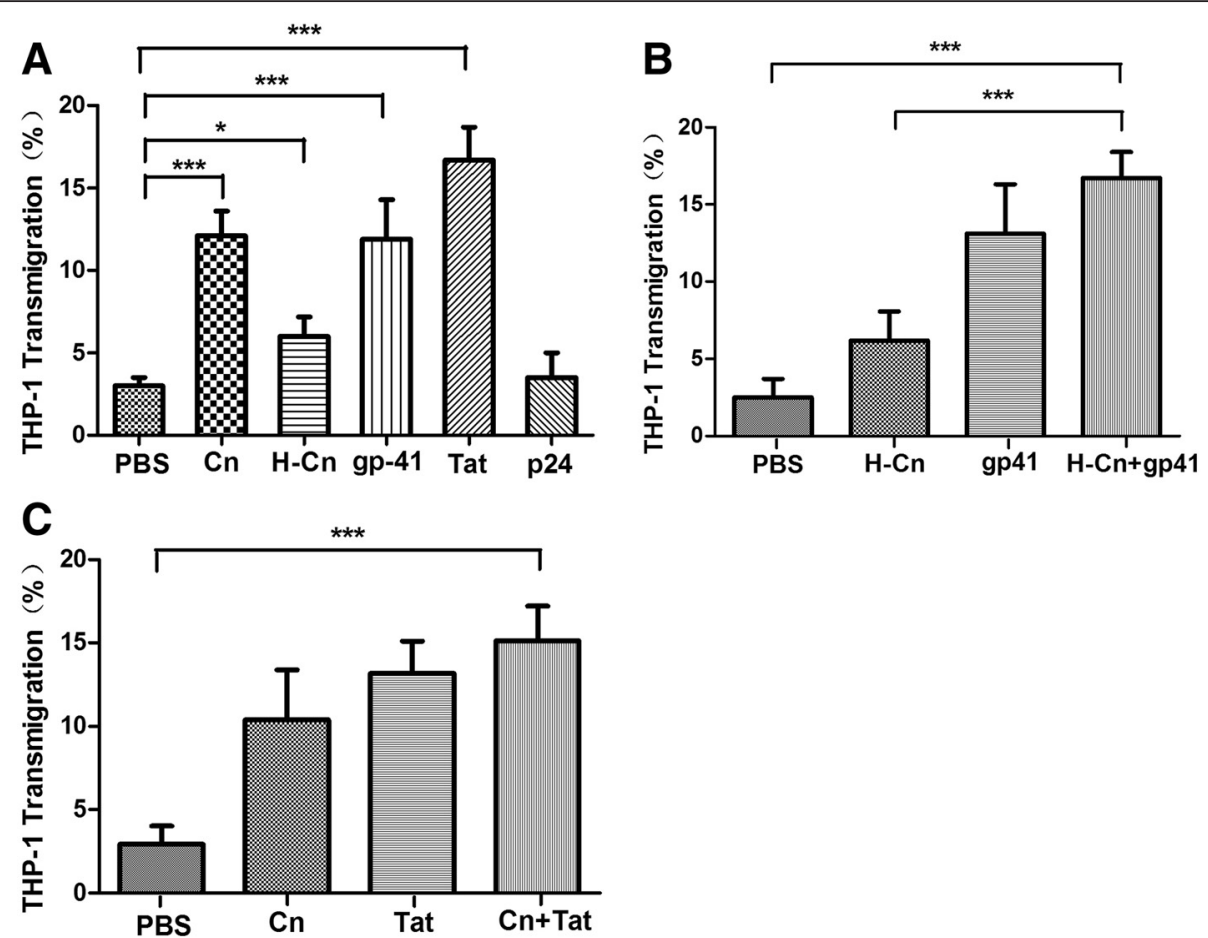

Fig. 4 Specificity of $\mathrm{Cn}$ and HIV gp41 in induced monocyte transmigration across HBMEC monolayers. a Monocytes transmigration rate of $\mathrm{Cn}$ $\mathrm{H}-\mathrm{Cn}$, HIV-1 gp41, HIV Tat, and HIV p24. HBMEC monolayers were treated with Cn, H-Cn, gp41, Tat or p24 respectively. Transmigration assays we performed as described as Methods section. $\mathbf{b}$ These are no synergistic effect of monocytes transmigration following BMEC treatment with $\mathrm{H}$-Cn and HIV-1 gp41. c These are no synergistic effect of monocytes transmigration following BMEC treatment with $\mathrm{Cn}$ and HIV Tat. The values represent the mean percent transmigrating THP-1 of triplicate samples and are representative of one experiment from three independent experiments showing similar data. ${ }^{*} P<0.05,{ }^{* * *} P<0.001$ compared with control

activity of monocyte. However, as shown in Fig. $4 \mathrm{a}-\mathrm{c}$, none of them could synergistically enhance the transmigration activity of monocyte. The synergistic effect was determined using the CalcuSyn Software as described above.

The enhancement of $\mathrm{Cn}$ and HIV-1 gp41-190 in transmigration of monocytes across the BBB is closely related to CD44

The HIV-1 envelope glycoprotein gp41 could up-regulate CD44 in AIDS patients with CM, which ultimately enhances the adhesion and invasion of $\mathrm{Cn}$ to BMECs $[18,53]$. In order to examine whether $\mathrm{Cn}$ and HIV-1 gp41-I90 enhance the transmigration of monocytes across the BBB is mediated by CD44, two different blockage approaches, genetic knockdown (KD-CD44 HBMEC) and chemical inhibition (CD44 inhibitor Bikunin) were used. KD-CD44 HBMEC was generated by the CRISPR Cas 9 genome editing technique, which is an effective way to down-regulate expression of protein in a broad variety of mammalian cells $[54,55]$. The down-regulating effect of Cas9 was measured at the protein level by Western blotting, approximately $77 \%$ knock-down was achieved (Fig. 5a, b). In order to ensure that the barrier remains intact in the absence of CD44, the integrity of the barrier of KD-CD44 HBMEC was evaluated by TEER. As shown in Fig. 5c, stimulation of $\mathrm{Cn}$ and
HIV-1 gp41-I90 alone or together has no significant effect on integrity of the barrier. Furthermore, we also performed Western blotting to examine the effect of down-regulated CD44 expression on tight junction protein ZO-1. As shown in Fig. 5d, the absence of CD44 has no effect on ZO-1 expression in HBMEC. THP-1 transmigration assays were performed with HBMEC, SC (scramble control) HBMEC and KD-CD44 HBMEC as described as Method section. As shown in Fig. 5e, significant reduction of THP-1 transmigration was observed in the KD-CD44 HBMEC groups.

Bikunin is a serine protease inhibitor, which was confirmed to have an inhibitory effect on CD44 [56, 57]. As shown in Fig. 5f, when the dosage of Bikunin was raised to $1 \mathrm{nM}$, it showed a significant inhibition on the enhancement of monocytes transmigration rate in $\mathrm{Cn}$ infectedHBMEC. Comparing to the control group (17.4\%), the monocytes transmigration rates of Bikunin group was down to 11 and $7.8 \%$, respectively with dosage $5 \mathrm{nM}$ and 20 nM (Fig. 5f). Similar, Bikunin could also remarkably block enhancement of HIV-1 gp41-I90 in transmigration of monocytes across BBB. Hence, we concluded that, HIV-1 gp41-I90 and Cn enhance the monocyte transmigration across BBB is mediated by CD44. 

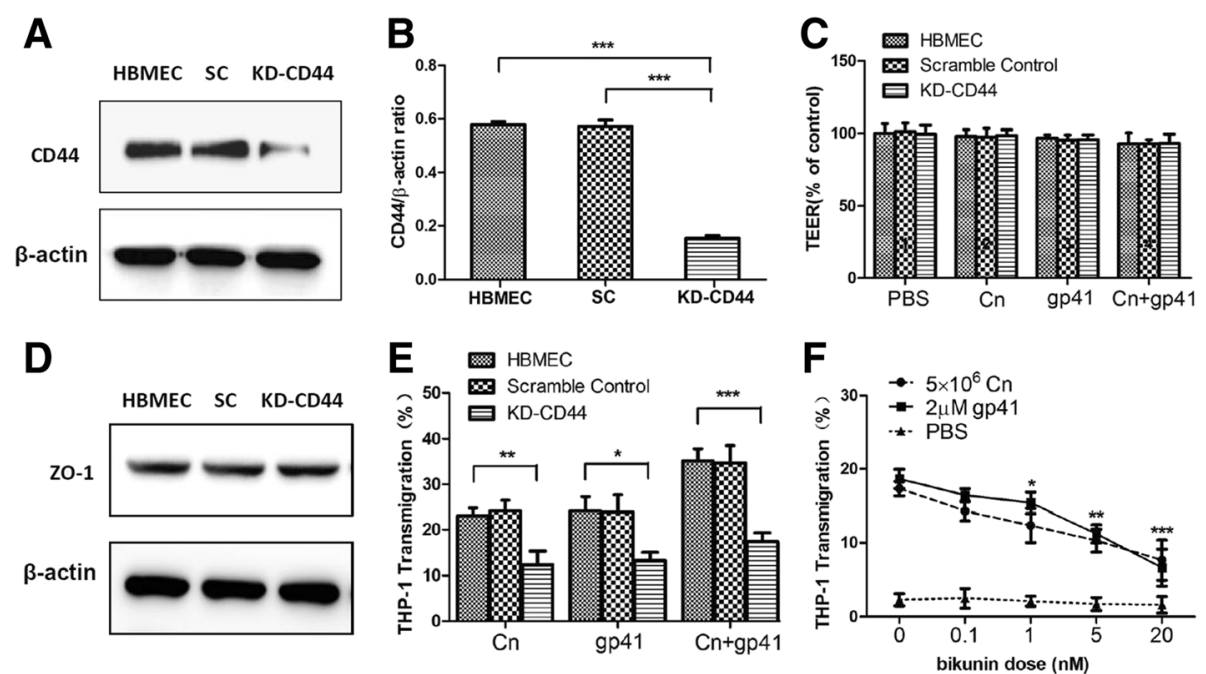

Fig. 5 Genetic (Knock-down) and chemical (inhibitor) blockage of CD44 results in a reduction of THP-1 transmigration across HBMEC. $\mathbf{a}, \mathbf{b}$ Down-regulating effect of the CRISPR Cas9 system was measured by Western blotting. $\beta$-actin was used as a loading control for each sample. Results showed a significant decrease $(77 \%)$ in the CD44/ $\beta$-actin optical density ratio (*** $P<0.001$ ). c Effect of Cn and HIV-1 gp41 on the BBB

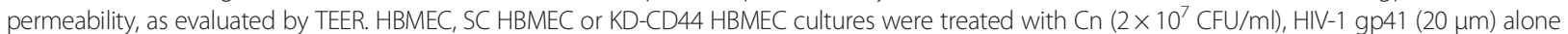
or $\mathrm{Cn}$ in combination with HIV-1 gp41 for $6 \mathrm{~h}$. Either Cn or HIV-1 gp41 alone or joint use of them had no significant effect on the permeability of HBMEC, SC HBMEC and KD-CD44. d Effect of down-regulated CD44 expression on ZO-1 in HBMEC. e Transmigration assays were performed with HBMEC, SC HBMEC and KD-CD44, a significant suppression of transmigration was observed in the KD-CD44 group. $\mathbf{f}$ Bikunin inhibits Cn-and HIV-1 gp41-190- induced THP-1 transmigration across HBMEC in a dose-dependent manner. An uninfected BMEC as a negative control was designed in the assay. Results are expressed as the mean and standard deviation of quadruplicate assays. $\left({ }^{*} P<0.05,{ }^{* *} P<0.01,{ }^{* * *} P<0.001\right)$

\section{HIV-1 gp41-190 and Cn induce up-regulation of CD44 and ICAM-1 on HBMEC}

After demonstrating the effect of $\mathrm{Cn}$ and HIV-1 gp41 in monocytes transmigration across BBB in vitro, we focused on the role of $\mathrm{Cn}$ and HIV-1 gp41 in up-regulation of endothelial adhesion molecules that might be involved in monocytes transmigration. Surface expression of endothelial adhesion molecules was studied by using two approaches, western blotting and whole-cell BA-ELISA. As shown in Fig. 6a, b, following $6 \mathrm{~h}$ exposure of HBMEC to $\mathrm{Cn}$ and HIV-1 gp41-I90, significantly increase in surface expression of ICAM-1 and CD44 was observed. The data of BA-ELISAs were similar to Western blotting, as shown in Fig. 6d, e, the highest expression level of ICAM-1 and CD44 were observed in HBMEC treated with $\mathrm{Cn}$ in combination with HIV-1 gp41-I90. Interestingly, as shown in Fig. 6c, expression of CD44 in KD-CD44 HBMEC was up-regulated significantly following co-exposure to $\mathrm{Cn}$ and HIV-1 gp41-I90, although there was a slight increase in CD44 upon treatment of Cn or HIV-1 gp41-I90 alone.

The threshold of induced monocytes transmigration and up-regulated CD44 expression by HIV-1 gp41

In the process of studying the effect of HIV-1 gp41-I90 on the transmigration of monocytes across the BBB in vitro, we were able to observe there is a limitation in the induced monocytes transmigration across $\mathrm{BBB}$ by HIV-1 gp41-190. As shown in Fig. 7a, there was very little increase in transmigration rate 26.24 to $26.81 \%$, when the concentration of HIV-1 gp41-I90 was increased from 20 to $25 \mu \mathrm{M}$. This indicates a saturation level of monocytes transmigration, when the HIV-1 gp41-I90 concentration is approaching $25 \mu \mathrm{M}$. We further performed a BA-ELISA to confirm the biological relevance of this finding. HBMECs were treated with different dose of HIV-1 gp41-I90 (from 2 to $25 \mu \mathrm{M}$ ), the whole-cell BA-ELISA were performed as described Methods section to assess the expression of CD44 on the surface of HBMEC. As we expected, there is also a limitation of CD44 expression when the concentration of HIV-1 gp41-I90 was increased from 20 to $25 \mu \mathrm{M}$ (Fig. 7b). Taken together, the results clearly demonstrate that there is a threshold in the enhancement of monocytes transmigration and over-expression of CD44 induced by HIV-1 gp41-190.

\section{Redistribution of CD44 to membrane rafts of HBMEC during $\mathrm{Cn}$ and HIV-1 gp41-190 exposure}

Adhesion molecules recruited to specialized microdomains of lipid rafts is important to regulate intracellular signaling and leukocyte transendothelial migration [58]. Thus, we tested whether $\mathrm{Cn}$ and/or gp41-190 could induce CD44 redistribution to the membrane lipid rafts of HBMEC. As CD44 could be a membrane receptor on HBMEC, we used density gradient centrifugation to fractionate membrane rafts. HBMECs treated by $\mathrm{Cn}$ and/or 

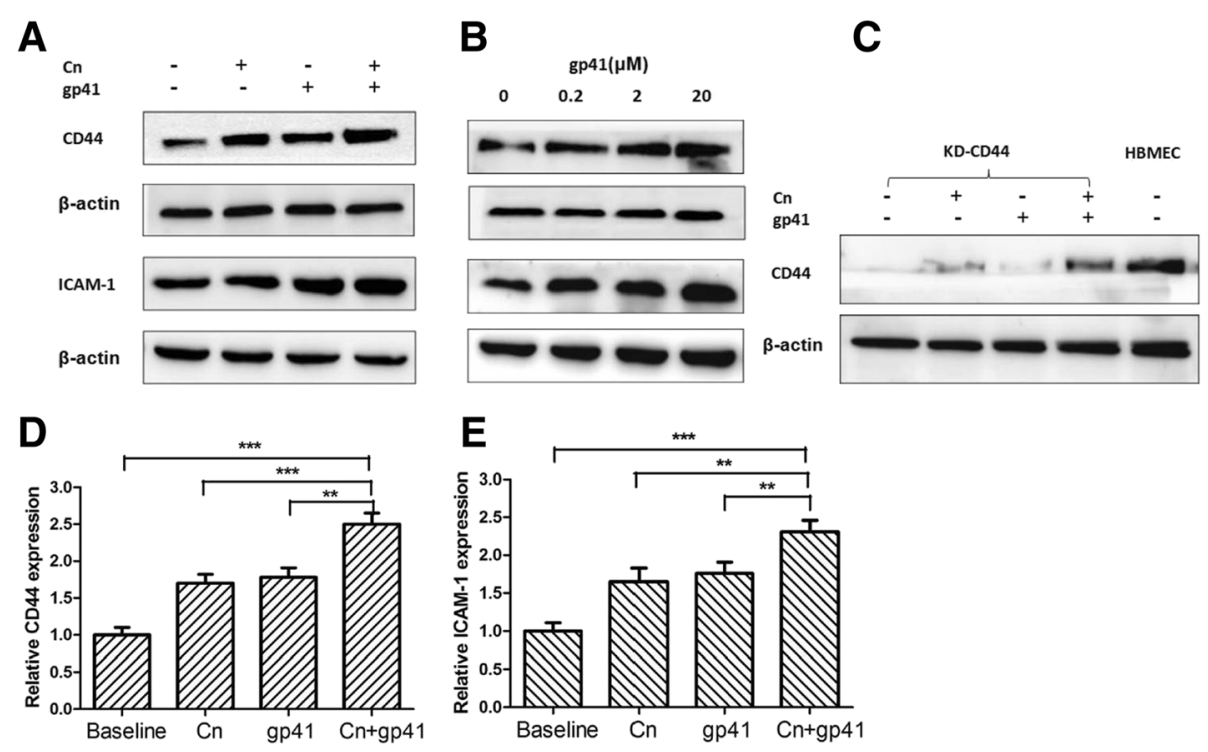

Fig. $6 \mathrm{Cn}$ and HIV-1 gp41 enhanced expression of CD44 and ICAM-1 on the HBMEC. Western blotting analyses were performed to measure the up-regulating effect of CD44 (a, c) and ICAM-1 (b) on HBMEC or KD-CD44 HBMEC following exposure to Cn and/or HIV-1 gp41. The $\beta$-actin was used as a loading control for each sample. Results showed a significant increase in the CD44/ $\beta$-actin optical density ratio $(P<0.01$ compared with control). Expression of ICAM-1 (d) and CD44 (e) was analyzed by BA-ELISAs. Assays were performed in triplicates. Results were expressed as an $\mathrm{n}$-fold increase of protein expression, taking the control as 1 . The significant differences between the treatment and control were marked with asterisks $\left({ }^{*} P<0.05,{ }^{* *} P<0.01,{ }^{* *} P<0.001\right)$

HIV-1 gp-41 were lysed in a buffer containing $1 \%$ Triton $\mathrm{X}-100$. The fractionation was performed in OptiPrep ${ }^{\mathrm{TM}}$ density gradient centrifugation. After centrifugation, detergent-insoluble membrane lipid raft fractions floated to the interphase between $0 \%$ and $20 \%$ OptiPrep $^{\mathrm{TM}}$ layers, peaking at fraction 2 in our study (asterisk in Fig. 8). The loading buffer floated to the top (fraction 1), but soluble proteins or cytoskeleton associated, detergent-insoluble proteins remained in the bottom fractions of the gradient (fractions 3-9). Protein blotting of each fraction was used to examine the distribution of protein components from
HBMEC extracts of the $\mathrm{Cn}$ and/or gp41-treated samples. As shown in Fig. 8, in untreated HBMEC, CD44 was primarily associated with soluble fractions (fractions 6-9). For the cells treated with either $\mathrm{Cn}$ and/or HIV-1 gp41-I90, a significant portion of CD44 had apparently relocated to the membrane rafts as observed in the fraction 2 . The result suggested that there was a reorganization of membrane rafts taking place during exposure to $\mathrm{Cn}$ and/or HIV-1 gp41-190, and CD44 became enriched in these membrane rafts on the surface of HBMEC, which facilitates the monocytes transmigrate across the BBB.
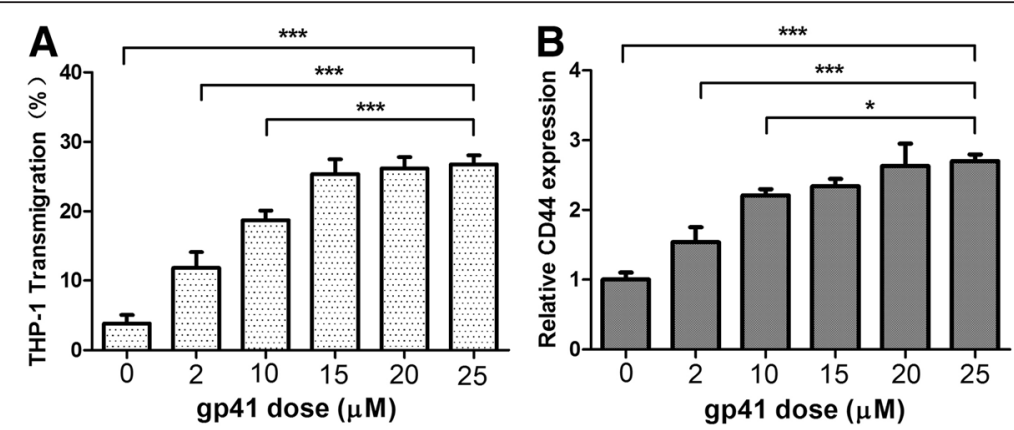

Fig. 7 There is a limitation in the induced transmigration of monocytes and up-regulated expression of CD44 by HIV-1 gp41-190. HBMEC were treated with different dose of HIV-1 gp41-190 (2-25 $\mu \mathrm{M})$ for $6 \mathrm{~h}$. Transmigration assays (a) and BA-ELISAs (b) were performed to assess whether transmigration of monocytes and expression of CD44 induced by HIV-1 gp41-190 is dose-dependent. The values represent the mean percent transmigrating THP-1 of triplicate samples and are representative of one experiment from three independent experiments showing similar data. $\left({ }^{*} P<0.05,{ }^{*} P<0.01,{ }^{* *} P<0.001\right)$ 


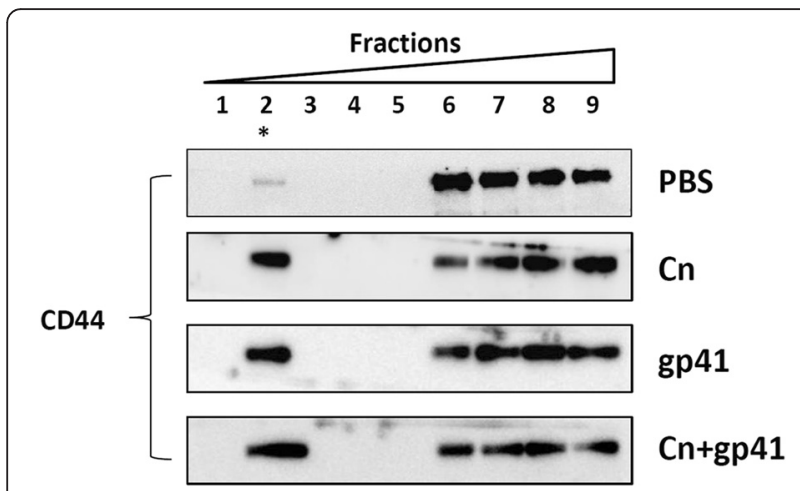

Fig. 8 Redistribution of CD44 to membrane rafts during HBMEC exposure to $\mathrm{Cn}$ and/or HIV-1 gp41-190. HBMECs were treated with either PBS or Cn, or HIV gp41-190 or both of them for $6 \mathrm{~h}$. The cells were then lysed in buffer containing $1 \%$ Triton X-100 on ice. Fractionation was performed in OptiPrep ${ }^{\mathrm{TM}}$ gradients, and nine fractions were collected. The lipid raft fractions are indicated by * in fraction 2. An equal volume of each sample was analysed by dot blots using antibodies against CD44. Redistribution of CD44 on the membrane rafts was observed in Cn and/or HIV-1 gp41-190 treated HBMECs

HIV-1 gp41-190 increased Cn-induced monocyte transmigration, the BBB permeability and injury in vivo To further validate the biological relevance of the in vitro assays, the role of HIV-1 gp41-I90 in the monocyte transmigration across the $\mathrm{BBB}$ induced by $\mathrm{Cn}$ was tested in the mouse model, as described in Methods section. Animals of the same age were injected with $\mathrm{Cn}\left(10^{6}\right.$ cells $)$ or HIV-1 gp41-I90 (10 $\mu \mathrm{g} / \mathrm{g}$ mouse weight) alone or $\mathrm{Cn}$ in combination with HIV-1 gp41-I90. Three indexes, monocytes transmigration, EB concentration in brain tissue and number of cBMEC in blood were used to evaluate the pathogenicities of CM. As shown in Fig. 9a-c, all above indexes shown highest mean in the mice injected with $\mathrm{Cn}$ in combination with HIV-1 gp41-I90. These results show that HIV-1 gp41-I90 and Cn could synergistically facilitate the monocyte transmigration, increase the BBB permeability (increased EB concentration in brain) and injury (increased cBMEC in blood).

Since most monocytes are recruited into brain parenchyma adjacent to blood vessels during the cryptococcal meningitis, next, we examined the effect of $\mathrm{Cn}$ and/or HIV-1 gp41-I90 on recruitment of monocytes into the brain parenchyma of mice. C57BL/6 mice were intravenously injected with $\mathrm{Cn}$ and/or HIV-1 gp41-I90 via the tail vein. After $24 \mathrm{~h}$ injection, mice were anaesthetized with ketamine and lidocaine, and the brains were removed and fixed in $4 \%$ neutralbuffered formalin. Immunohistochemistry analysis was performed as described as Methods section. As shown in Fig. 10, expose to Cn and/or HIV-1 gp41-I90 was able to significantly increase monocytes transmigration across the $\mathrm{BBB}$. These data suggested that

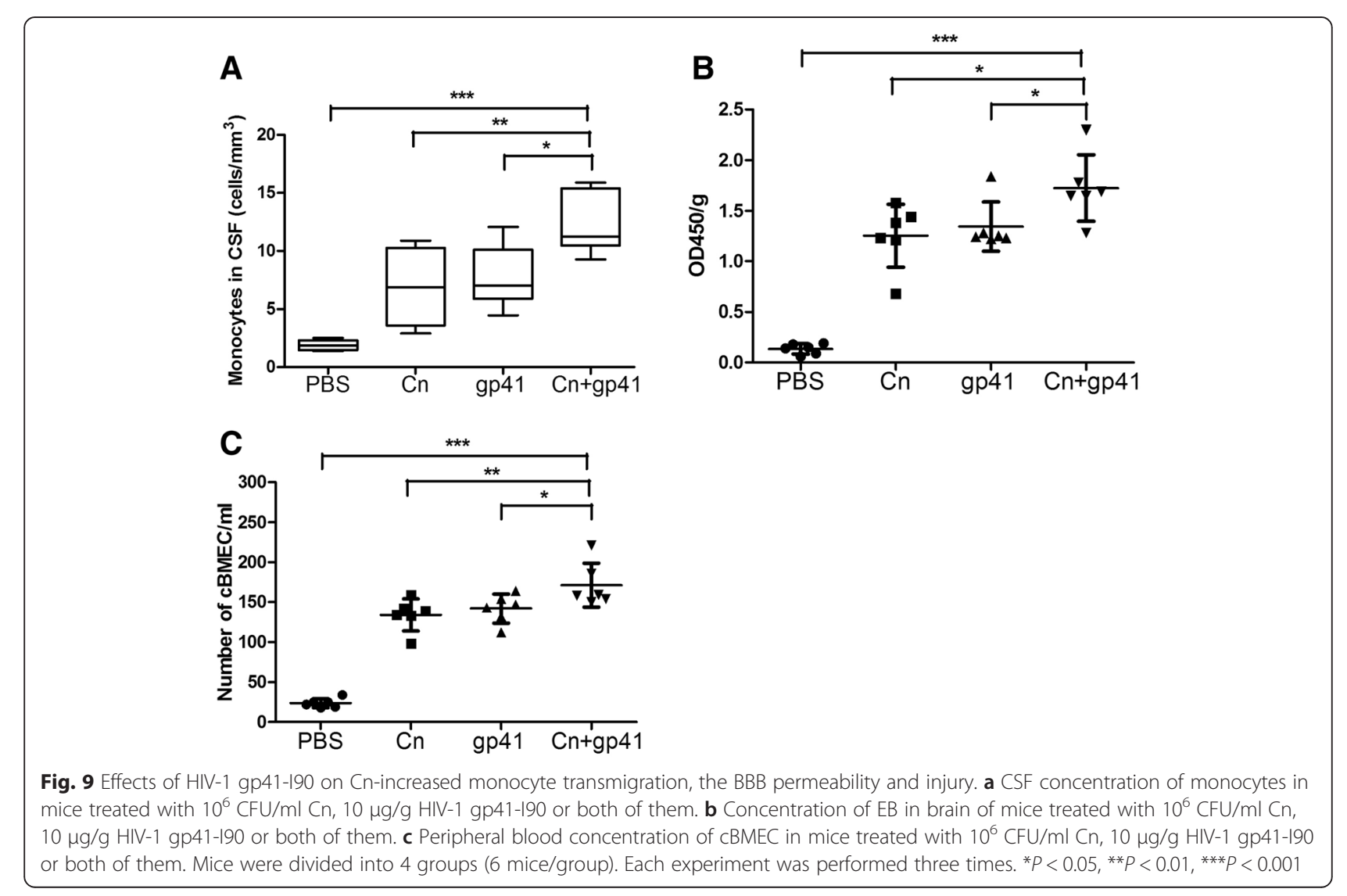




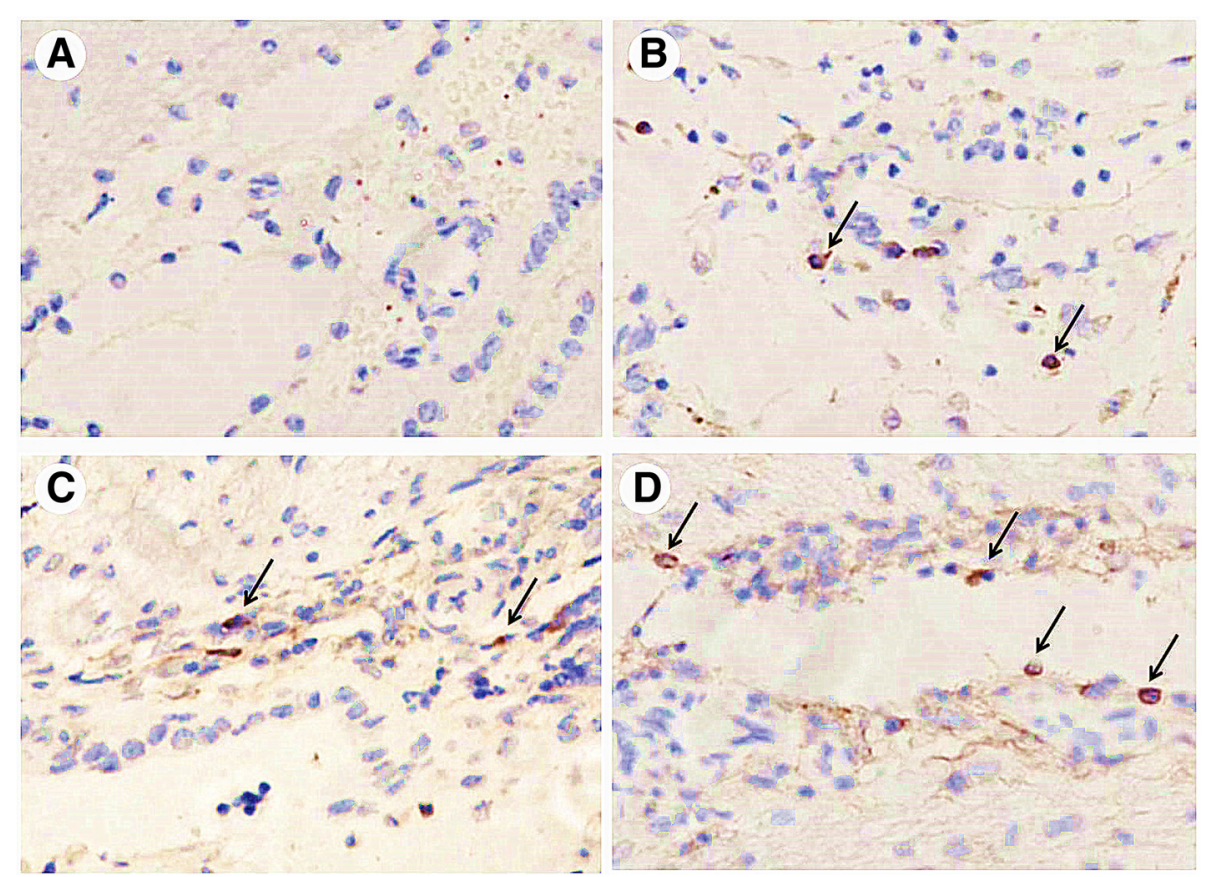

Fig. 10 Recruitment of monocytes into the brain parenchyma of mice treated with Cn and/or HIV-1 gp41-190. C57BL/6 mice were intravenously injected with $\mathrm{Cn}$ and/or HIV-1 gp41-I90 via the tail vein. After $24 \mathrm{~h}$ injection, mice were anaesthetized with ketamine and lidocaine, and the brains were removed and fixed in $4 \%$ neutral buffered formalin. Immunohistochemistry analysis was performed as described as Methods section. a Normal brain. b Brian of mice infected with Cn. c Brian of mice treated with HIV-1 gp41-190. d Brian of mice treated with Cn + HIV-1 gp41-190. Arrows indicate infiltrating monocytes. Images are $400 x$

expose to HIV-1 gp41-I90 increased Cn-induced monocytes recruitment into CNS.

\section{Discussion}

$\mathrm{Cn}$ is an opportunistic pathogen, which causes fatal meningoencephalitis, especially in AIDS patients. In order to cause meningoencephalitis, $\mathrm{Cn}$ must cross the BBB. A great deal of evidence supports the existence of the Trojan horse model of BBB transmigration of $\mathrm{Cn}$. (1) Cn can survive in phagocytic cells via active phagosomal extrusion and spread to the phagocytes [59, 60]; (2) The incidence rate of fungemia and meningoencephalitis is higher in HIV-1-infected patients than that in HIV-1-negative patients because HIV-1 can cause severe monocyte dysfunction in host [61-63]; (3) Cn was carried and transported by circulating phagocytes in the murine model of cryptococcosis in a previous study by Chrétien F. et al. [64]. (4) Cn is a facultative intracellular pathogen and has been shown to survive and multiply inside phagocytes in vitro [65]. Previous research had shown that HIV-1 infection is able to increase the monocyte capacity to migrate across the $\mathrm{BBB}$ [36]. In present study, we have suggested that $\mathrm{Cn}$ and/or HIV-1 gp41-I90 is able to enhance the transmigration activities of monocytes across $\mathrm{BBB}$ by using the in vitro and in vivo BBB models [66]. Importantly, we found that HIV1 gp41-I90 was able to synergistically enhance the transmigration activity of monocytes in HBMEC infected with $\mathrm{Cn}$ and in mice with $\mathrm{Cn}$-caused meningoencephalitis. Thus, we have firstly demonstrated the relationship between HIV-1, Cn and monocytes, which point out a new potential mechanism of invasion for this pathogenic fungus into the brain tissues of HIV-1-infected patients.

Initially, we demonstrated that the transmigration of monocytes across the $\mathrm{BBB}$ in vitro could besynergistically enhanced by HIV-1 gp41 protein and $\mathrm{Cn}$. The specificity of the synergistic effect is further confirmed by transmigration assays. Two experiments were designed. In the first experiment, we used $\mathrm{H}-\mathrm{Cn}$ to examine whether $\mathrm{H}-\mathrm{Cn}$ and HIV-1 gp41 could synergistically enhance the transmigrate ability of monocytes. Our results have shown that there is no synergistic effect on the transmigration of monocytes with a combination of $\mathrm{H}-\mathrm{Cn}$ and gp41. Interestingly, we found that $\mathrm{H}-\mathrm{Cn}$ could also increase monocyte transmigration ability. In the second experiment, HIV Tat and p24 proteins were used. HIV Tat is a regulatory protein that enhances viral transcription and replication, which plays a multifaceted role in pathogenesis of HIV infection, including favouring viral infection, contributing to inflammatory responses and inducing monocyte invasion into the brain [67-70]. Notwithstanding, we found there is no synergistic effect on enhancement of monocyte transmigration upon treatment by a combination of $\mathrm{Cn}$ and HIV-1 Tat protein. Similarly, HIV p24, which is a component of the HIV particle capsid, also has no synergistic effect on Cn-mediated 
enhancement of monocyte transmigration. Taken together, these results suggest that the synergistic enhancement by the HIV-1 gp41 protein on monocyte transmigration across the Cn-infected BBB is viral factor-dependent. This is most likely due to the fact that both HIV-1 gp41 and Cn may elicit a similar signal, such as up-regulating CD44 and ICAM-1 expression (Fig. 6), activating membrane lipid rafts (Fig. 8) and NF-kB [44], to facilitate the transmigration of monocytes. Thus, we speculate that the ectodomain of HIV-1 gp41 may play a role as a trans-predilection factor for cryptococcal CNS invasion, suggesting that the HIV-1 fusion inhibitors targeting gp41, such as T20 and C34, may be helpful in the prevention and treatment of cryptococcal meningitis in HIV/AIDS patients.

CD44 is a well-known type I transmembrane glycoprotein and functions as the major hyaluronan receptor, which is widely distributed in a variety of endothelial cells, mesenchymal cells, hematopoietic stem cells and mesodermal cells and tissues. Although, alternative splicing can produce a large number of different isoforms, they all retain the hyaluronan-binding link-homology region and a common transmembrane and cytoplasmic domain [19]. Recent studies have demonstrated that, the gene that encodes capsule hyaluronic acid synthase is a key virulence gene of $\mathrm{Cn}$. The transmigration process of $\mathrm{Cn}$ across the $\mathrm{BBB}$ rely on HA binding to the BMEC receptor $C D 44$, which activates the host signal pathway to induce cytoskeleton rearrangement required for $\mathrm{Cn}$ invasion $[71,72]$. In present study, we used the CRISPRCas9 system and CD44 inhibitor to examine whether the enhancement of $\mathrm{Cn}$ and HIV-1 gp41-I90 in transmigration of monocytes across the BBB is related to CD44. Indeed, our results revealed that CD44 was involved in the enhancement of monocyte transmigration across the BBB by $\mathrm{Cn}$ and HIV-1 gp41.

Beside the effect of inducing monocyte transmigration across the BBB in vitro, in present study, we also found that $\mathrm{Cn}$ and/or HIV-1 gp41 could enhance CD44 redistribution to the membrane lipid rafts and up-regulate the expression level of ICAM-1 and CD44, which are two major endothelial adhesion molecules long known for its importance in facilitating leukocyte transmigration. These findings indicate that $\mathrm{Cn}$ and HIV-1 gp41-induced migration of monocytes across BMEC in a coordinate manner with up-regulation of ICAM-1 and CD44. Hence, we derived the conclusion that, HBMEC co-exposed with $\mathrm{Cn}$ and HIV-1 gp41 exhibited re-distribution of CD44 and over-expression of CD44 and ICAM-1, which lead to enhancement of the adhesion and transmigration rates of monocytes and facilitate cerebral invasion of $\mathrm{Cn}$.

During the process of studying the effect of HIV-1 gp41-I90 on the transmigration of monocytes across the $\mathrm{BBB}$, we found the facilitation of HIV-1 gp41-I90 induced transmigration of monocytes is dose-dependent. When the concentration of HIV-1 gp41 was raised to a certain level, the facilitation get subdued, which remind us that, there is a threshold in the over-expression of CD44 induced by HIV-1 gp41-I90. In order to test the above assumption, different doses of HIV-1 gp41 $(2-25 \mu \mathrm{M})$ was added to the HBMEC monolayers to observe the transmigration activities of monocyte. These results showed that the facilitation induced by HIV-1 gp41-I90 was significantly saturated with the higher concentrations of the recombinant protein (Fig. 7a). Furthermore, we performed BA-ELISAs to examine whether the over-expression of CD44 induced by HIV-1 gp41-190 is also dose-dependent. As we expected, the expression level of CD44 on HBMEC could became saturated when the concentration of HIV-1 gp41-I90 was increased from 20-25 $\mu \mathrm{M}$ (Fig. 7b). These results have profound clinical significance in antiretroviral therapies for HIV-associated Cryptococoal meningoencephalitis, as it suggests that adherence to antiretroviral therapies may minimize the risk of Cryptococoal neurologic disease.

\section{Conclusions}

In conclusion, HIV-1 gp41-I90 and $\mathrm{Cn}$ is able to promote the adhesion and transmigration activities of monocyte, and the co-exposure of HIV-1 gp41-I90 and $\mathrm{Cn}$ further accelerate the adhesion and transmigration activities of monocyte. This may result in a deteriorating cryptococcosis in the infected host. The details for how the HIV-1 enhances cryptococcal invasion into the human brain remain unclear. However, our studies provide the enlightenments to establish the exact mechanism of inflammatory responses induced by the HIV-1 gp41-I90 ectodomain often co-morbid with $\mathrm{Cn}$ that lead to HIV1-associated CM, and provide a theoretical basis for new ways to effectively combat opportunistic infections of the central nervous system in AIDS patients.

\section{Competing interests \\ The authors declare that they have no competing interests.}

\section{Authors' contributions}

$\mathrm{HC}$ and $\mathrm{SH}$ conceived and designed the experiment, $\mathrm{XH}, \mathrm{XS}, \mathrm{SPK}, \mathrm{LZ}, \mathrm{YL}$ and QZ performed the experiment, XH, XS, SB, SPK, QZ, YL, JQ, ZL, CM and YX analyzed the data, $\mathrm{SH}$ contributed reagents/materials/analysis tools, SPK, $\mathrm{XH}$, $X S, S B, L Z, M L, L D, S H$ and $H C$ participated in its design and coordination and helped to draft the manuscript. All authors read and approved the final manuscript.

\section{Acknowledgements}

This project was financially supported by the National Natural Science Foundation of China (No. 81171644 to H. Cao), and Key Laboratory of Prevention and Control of Emerging Infectious Diseases of Guangdong Higher Education Institutes, Southern Medical University (KLGHEl, KLB09007). We also thank Bao Zhang to generous providing lentiviral packaging vectors pCMV-dR8.2 dvpr and pCMV-VSV-G and lentiCRISPRV2 plasmid.

\section{Author details}

'Department of Microbiology, Guangdong Provincial Key Laboratory of Tropical Disease Research, School of Public Health and Tropical Medicine, Southern Medical University, Guangzhou 510515, China. ${ }^{2}$ The Second School 
of Clinical Medicine, Southern Medical University, Guangzhou 510515, China. ${ }^{3}$ Saban Research Institute, Children's Hospital Los Angeles, University of Southern California, Los Angeles, CA 90027, USA.

Received: 8 September 2015 Accepted: 15 February 2016 Published online: 20 February 2016

\section{References}

1. Chen SH, Stins MF, Huang S-H, Chen YH, Kwon-Chung K, Chang Y, et al. Cryptococcus neoformans induces alterations in the cytoskeleton of human brain microvascular endothelial cells. J Med Microbiol. 2003: 52(11):961-70

2. Jong A, Wu CH, Prasadarao NV, Kwon-Chung KJ, Chang YC, Ouyang Y, et al. Invasion of Cryptococcus neoformans into human brain microvascular endothelial cells requires protein kinase C-a activation. Cell Microbiol. 2008; 10(9):1854-65.

3. Chuck SL, Sande MA. Infections with Cryptococcus neoformans in the acquired immunodeficiency syndrome. N Engl J Med. 1989;321(12):794-9.

4. Mitchell TG, Perfect JR. Cryptococcosis in the era of AIDS-100 years after the discovery of Cryptococcus neoformans. Clin Microbiol Rev. 1995;8(4):515-48.

5. Mirza SA, Phelan M, Rimland D, Graviss E, Hamill R, Brandt ME, et al. The changing epidemiology of cryptococcosis: an update from population-based active surveillance in 2 large metropolitan areas, 1992-2000. Clin Infect Dis. 2003:36(6):789-94.

6. Chen SC. Cryptococcosis in Australasia and the treatment of cryptococcal and other fungal infections with liposomal amphotericin B.J Antimicrob Chemother. 2002;49 suppl 1:57-61.

7. Dromer F, Mathoulin-Pélissier S, Fontanet A, Ronin O, Dupont B, Lortholary O, et al. Epidemiology of HIV-associated cryptococcosis in France (1985-2001): comparison of the pre-and post-HAART eras. Aids. 2004;18(3):555-62

8. Corbett EL, Churchyard GJ, Charalambos S, Samb B, Moloi V, Clayton TC, et al. Morbidity and mortality in South African gold miners: impact of untreated disease due to human immunodeficiency virus. Clin Infect Dis. 2002;34(9):1251-8.

9. Amornkul PN, Hu DJ, Tansuphasawadikul S, Lee S, Eampokalap B, Likanonsakul $S$, et al. Human immunodeficiency virus type 1 subtype and other factors associated with extrapulmonary Cryptococcosis among patients in Thailand with AIDS. AIDS Res Hum Retrovir. 2003;19(2):85-90.

10. Chen $K-Y$, Ko S-C, Hsueh P-R, Luh K-T, Yang P-C. Pulmonary fungal infection: emphasis on microbiological spectra, patient outcome, and prognostic factors. Chest J. 2001;120(1):177-84.

11. Ngamskulrungroj $P$, Chang $Y$, Hansen B, Bugge C, Fischer E, Kwon-Chung $\mathrm{KJ}$. Characterization of the chromosome 4 genes that affect fluconazoleinduced disomy formation in Cryptococcus neoformans. PLoS One. 2012; 7(3), e33022.

12. Razakandrainibe R, Combes V, Grau GE, Jambou R. Crossing the wall: the opening of endothelial cell junctions during infectious diseases. Int J Biochem Cell Biol. 2013;45(7):1165-73.

13. Jong A, Wu CH, Shackleford GM, Kwon-Chung KJ, Chang YC, Chen HM, et al. Involvement of human CD44 during Cryptococcus neoformans infection of brain microvascular endothelial cells. Cell Microbiol. 2008, 10(6):1313-26

14. Jong A, Wu C-H, Gonzalez-Gomez I, Kwon-Chung KJ, Chang YC, Tseng $\mathrm{H}-\mathrm{K}$, et al. Hyaluronic acid receptor CD44 deficiency is associated with decreased Cryptococcus neoformans brain infection. J Biol Chem. 2012; 287(19):15298-306. doi:10.1074/jbc.M112.353375.

15. Long M, Huang S-H, Wu C-H, Shackleford GM, Jong A. Lipid raft/caveolae signaling is required for Cryptococcus neoformans invasion into human brain microvascular endothelial cells. J Biomed Sci. 2012;19(1):19.

16. Huang S-H, Long M, Wu C-H, Kwon-Chung KJ, Chang YC, Chi F, et al. Invasion of Cryptococcus neoformans into human brain microvascular endothelial cells is mediated through the lipid rafts-endocytic pathway via the dual specificity tyrosine phosphorylation-regulated kinase 3 (DYRK3). J Biol Chem. 2011:286(40):34761-9.

17. Jong AY, Wu C-H, Jiang S, Feng L, Chen H-M, Huang S-H. HIV-1 gp41 ectodomain enhances Cryptococcus neoformans binding to HBMEC. Biochem Biophys Res Commun. 2007;356(4):899-905

18. Huang $\mathrm{SH}, \mathrm{Wu} \mathrm{CH}$, Jiang S, Bahner I, Lossinsky AS, Jong AY. HIV-1 gp41 ectodomain enhances Cryptococcus neoformans binding to human brain microvascular endothelial cells via gp41 core-induced membrane activities. Biochem J. 2011;438(3):457-66. doi:10.1042/bj20110218.
19. Thorne RF, Legg JW, Isacke CM. The role of the CD44 transmembrane and cytoplasmic domains in co-ordinating adhesive and signalling events. J Cell Sci. 2004;117(3):373-80.

20. Chang YC, Stins MF, McCaffery MJ, Miller GF, Pare DR, Dam T, et al. Cryptococcal yeast cells invade the central nervous system via transcellular penetration of the blood-brain barrier. Infect Immun. 2004;72(9):4985-95.

21. Huang S-H, Wass C, Fu Q, Prasadarao NV, Stins M, Kim KS. Escherichia coli invasion of brain microvascular endothelial cells in vitro and in vivo: molecular cloning and characterization of invasion gene ibe10. Infect Immun. 1995;63(11):4470-5.

22. Kim KS. E. coli invasion of brain microvascular endothelial cells as a pathogenetic basis of meningitis, Bacterial invasion into eukaryotic cells. New York: Springer; 2000. p. 47-59.

23. Prasadarao NV, Wass CA, Stins MF, Shimada H, Kim KS. Outer membrane protein A-promoted actin condensation of brain microvascular endothelial cells is required for Escherichia coli invasion. Infect Immun. 1999;67(11):5775-83.

24. Nizet V, Kim K, Stins M, Jonas M, Chi EY, Nguyen D, et al. Invasion of brain microvascular endothelial cells by group B streptococci. Infect Immun. 1997; 65(12):5074-81.

25. Greiffenberg L, Goebel W, Kim KS, Weiglein I, Bubert A, Engelbrecht F, et al. Interaction of Listeria monocytogeneswith human brain microvascular endothelial cells: InIB-dependent invasion, long-term intracellular growth, and spread from macrophages to endothelial cells. Infect Immun. 1998; 66(11):5260-7.

26. Pujol C, Eugene E, De Saint ML, Nassif X. Interaction of Neisseria meningitidis with a polarized monolayer of epithelial cells. Infect Immun. 1997;65(11):4836-42

27. Jong AY, Stins MF, Huang S-H, Chen SH, Kim KS. Traversal of Candida albicans across human blood-brain barrier in vitro. Infect Immun. 2001;69(7): 4536-44.

28. Charlier C, Chrétien F, Baudrimont M, Mordelet E, Lortholary O, Dromer F. Capsule structure changes associated with Cryptococcus neoformans crossing of the blood-brain barrier. Am J Pathol. 2005;166(2):421-32.

29. Olszewski MA, Noverr MC, Chen G-H, Toews GB, Cox GM, Perfect JR, et al. Urease expression by Cryptococcus neoformans promotes microvascular sequestration, thereby enhancing central nervous system invasion. Am J Pathol. 2004;164(5):1761-71.

30. Lonsdale-Eccles JD, Grab DJ. Trypanosome hydrolases and the blood-brain barrier. Trends Parasitol. 2002;18(1):17-9.

31. Grab DJ, Nikolskaia O, Kim YV, Lonsdale-Eccles JD, Ito S, Hara T, et al. African trypanosome interactions with an in vitro model of the human blood-brain barrier. J Parasitol. 2004;90(5):970-9.

32. Dallasta LM, Pisarov LA, Esplen JE, Werley JV, Moses AV, Nelson JA, et al. Blood-brain barrier tight junction disruption in human immunodeficiency virus-1 encephalitis. Am J Pathol. 1999:155(6):1915-27.

33. Erlander $\mathrm{S}$. The solution to the seven mysteries of AIDS; The 'Trojan Horse'. Med Hypotheses. 1995;44(1):1-9.

34. Lane JH, Sasseville VG, Smith MO, Vogel P, Pauley DR, Heyes MP, et al. Neuroinvasion by simian immunodeficiency virus coincides with increased numbers of perivascular macrophages/microglia and intrathecal immune activation. J Neurovirol. 1996;2(6):423-32.

35. Charlier C, Nielsen K, Daou S, Brigitte M, Chretien F, Dromer F. Evidence of a role for monocytes in dissemination and brain invasion by Cryptococcus neoformans. Infect Immun. 2009;77(1):120-7.

36. Wang $\mathrm{H}$, Sun J, Goldstein $\mathrm{H}$. Human immunodeficiency virus type 1 infection increases the in vivo capacity of peripheral monocytes to cross the blood-brain barrier into the brain and the in vivo sensitivity of the blood-brain barrier to disruption by lipopolysaccharide. J Virol. 2008; 82(15):7591-600.

37. Sheng-He H, Chu-Hua W, Shibo J, Ingrid B, Albert SL, Ambrose YJ. HIV-1 gp41 ectodomain enhances Cryptococcus neoformans binding to human brain microvascular endothelial cells via gp41 core-induced membrane activities. Biochem J. 2011;438(3):457-66.

38. Blasi E, Mazzolla R, Barluzzi R, Mosci P, Bistoni F. Anticryptococcal resistance in the mouse brain: beneficial effects of local administration of heat-inactivated yeast cells. Infect Immun. 1994;62(8):3189-96.

39. Huang $\mathrm{SH}$, Jong AY. Cellular mechanisms of microbial proteins contributing to invasion of the blood-brain barrier. Cell Microbiol. 2001;3(5):277-87.

40. Huang S-H, Stins MF, Kim KS. Bacterial penetration across the blood-brain barrier during the development of neonatal meningitis. Microbes Infect. 2000;2(10):1237-44. 
41. Huang S-H, Wan Z-S, Chen Y-H, Jong AY, Kim KS. Further characterization of Escherichia coli brain microvascular endothelial cell invasion gene ibeA by deletion, complementation, and protein expression. J Infect Dis. 2001;183(7): 1071-8.

42. Huang S-H, Chen Y-H, Fu Q, Stins M, Wang Y, Wass C, et al. Identification and characterization of an Escherichia coli invasion gene locus, ibeB, required for penetration of brain microvascular endothelial cells. Infect Immun. 1999;67(5):2103-9.

43. Che X, Chi F, Wang L, Jong TD, Wu CH, Wang X, et al. Involvement of IbeA in meningitic Escherichia coli K1-induced polymorphonuclear leukocyte transmigration across brain endothelial cells. Brain Pathol. 2011;21(4) 389-404. doi:10.1111/j.1750-3639.2010.00463.x.

44. Zhang B, Yu J-Y, Liu L-Q, Peng L, Chi F, Wu C-H, et al. Alpha7 nicotinic acetylcholine receptor is required for blood-brain barrier injury-related CNS disorders caused by Cryptococcus neoformans and HIV-1 associated comorbidity factors. BMC Infect Dis. 2015;15(1):352.

45. Lu T-S, Avraham HK, Seng S, Tachado SD, Koziel H, Makriyannis A, et al. Cannabinoids inhibit HIV-1 Gp120-mediated insults in brain microvascular endothelial cells. J Immunol. 2008;181(9):6406-16.

46. Ziegler-Heitbrock L, Ancuta P, Crowe S, Dalod M, Grau V, Hart DN, et al. Nomenclature of monocytes and dendritic cells in blood. Blood. 2010; 116(16):e74-80.

47. Huang S-H, Wang L, Chi F, Wu C-H, Cao H, Zhang A, et al. Circulating brain microvascular endothelial cells (CBMECS) as potential biomarkers of the bloodbrain barrier disorders caused by microbial and non-microbial factors. 2013.

48. Chi F, Wang L, Zheng X, Wu CH, Jong A, Sheard MA, et al. Meningitic Escherichia coli K1 penetration and neutrophil transmigration across the blood-brain barrier are modulated by alpha7 nicotinic receptor. PLoS One. 2011;6(9), e25016. doi:10.1371/journal.pone.0025016.

49. Jackson C, Garbett P, Nissen B, Schrieber L. Binding of human endothelium to Ulex europaeus I-coated Dynabeads: application to the isolation of microvascular endothelium. J Cell Sci. 1990;96(2):257-62.

50. Ben-Zvi A, Lacoste B, Kur E, Andreone BJ, Mayshar Y, Yan H, et al. Mfsd2a is critical for the formation and function of the blood-brain barrier. Nature. 2014;509(7501):507-11.

51. Sabiiti W, May RC. Mechanisms of infection by the human fungal pathogen Cryptococcus neoformans. Future Microbiol. 2012;7(11):1297-313.

52. Yu J-Y, Zhang B, Peng L, Wu C-H, Cao H, Zhong JF, et al. Repositioning of memantine as a potential novel therapeutic agent against meningitic E. Coli-induced pathogenicities through disease-associated Alpha7 cholinergic pathway and RNA sequencing-based transcriptome analysis of host inflammatory responses. PLoS One. 2015;10(5), e0121911. doi:10.1371/journal. pone.0121911.

53. Long M, Cao H, Jong A. Effect of HIV-1gp41 ectodomain on Cryptococcus neoformans-induced cytoskeletal changes in human brain microvascular endothelial cells. J Southern Med Univ. 2011;31(3):478-81.

54. Ran FA, Hsu PD, Wright J, Agarwala V, Scott DA, Zhang F. Genome engineering using the CRISPR-Cas9 system. Nat Protoc. 2013;8(11):2281-308.

55. Shalem O, Sanjana NE, Hartenian E, Shi X, Scott DA, Mikkelsen TS, et al. Genome-scale CRISPR-Cas9 knockout screening in human cells. Science. 2014;343(6166):84-7.

56. Fries E, Blom AM. Bikunin—not just a plasma proteinase inhibitor. Int J Biochem Cell Biol. 2000:32(2):125-37.

57. Wakahara K, Kobayashi H, Yagyu T, Matsuzaki H, Kondo T, Kurita N, et al. Bikunin down-regulates heterodimerization between CD44 and growth factor receptors and subsequently suppresses agonist-mediated signaling. J Cell Biochem. 2005;94(5):995-1009

58. Martinelli R, Newton G, Carman CV, Greenwood J, Luscinskas FW. Novel Role of CD47 in Rat Microvascular Endothelium Signaling and Regulation of T-Cell Transendothelial Migration. Arterioscler Thromb Vasc Biol. 2013;33(11):2566-76.

59. Alvarez M, Casadevall A. Phagosome extrusion and host-cell survival after Cryptococcus neoformans phagocytosis by macrophages. Curr Biol. 2006; 16(21):2161-5

60. Ma H, Croudace JE, Lammas DA, May RC. Expulsion of live pathogenic yeast by macrophages. Curr Biol. 2006;16(21):2156-60.

61. Monari C, Baldelli F, Pietrella D, Retini C, Tascini C, Francisci D, et al. Monocyte dysfunction in patients with acquired immunodeficiency syndrome (AIDS) versus Cryptococcus neoformans. J Infect. 1997;35(3):257-63.

62. Harriso TS, Levit SM. Mechanisms of impaired anticryptococcal activity of monocytes from donors infected with human immunodeficiency virus. J Infect Dis. 1997;176(2):537-40.
63. Dromer F, Mathoulin-Pélissier S, Launay O, Lortholary O, Group FCS. Determinants of disease presentation and outcome during cryptococcosis: the CryptoA/D study. PLoS Med. 2007:4(2), e21.

64. Chrétien F, Lortholary O, Kansau I, Neuville S, Gray F, Dromer F. Pathogenesis of cerebral Cryptococcus neoformans infection after fungemia. J Infect Dis. 2002;186(4):522-30.

65. Tucker SC, Casadevall A. Replication of Cryptococcus neoformans in macrophages is accompanied by phagosomal permeabilization and accumulation of vesicles containing polysaccharide in the cytoplasm. Proc Natl Acad Sci. 2002;99(5):3165-70.

66. Steinmann U, Borkowski J, Wolburg H, Schroppel B, Findeisen P, Weiss C, et al. Transmigration of polymorphnuclear neutrophils and monocytes through the human blood-cerebrospinal fluid barrier after bacterial infection in vitro. J Neuroinflammation. 2013;10(1):31.

67. Debaisieux S, Rayne F, Yezid H, Beaumelle B. The Ins and Outs of HIV-1 Tat. Traffic. 2012;13(3):355-63

68. Weiss JM, Nath A, Major EO, Berman JW. HIV-1 Tat induces monocyte chemoattractant protein-1-mediated monocyte transmigration across a model of the human blood-brain barrier and up-regulates CCR5 expression on human monocytes. J Immunol. 1999;163(5):2953-9.

69. Xiao H, Neuveut C, Tiffany HL, Benkirane M, Rich EA, Murphy PM, et al. Selective CXCR4 antagonism by Tat: implications for in vivo expansion of coreceptor use by HIV-1. Proc Natl Acad Sci. 2000;97(21):11466-71.

70. Conant K, Garzino-Demo A, Nath A, McArthur JC, Halliday W, Power C, et al Induction of monocyte chemoattractant protein-1 in HIV-1 Tat-stimulated astrocytes and elevation in AIDS dementia. Proc Natl Acad Sci. 1998:95(6): 3117-21.

71. Jong $\mathrm{A}, \mathrm{Wu} \mathrm{CH}$, Chen HM, Luo F, Kwon-Chung KJ, Chang YC, et al. Identification and characterization of CPS1 as a hyaluronic acid synthase contributing to the pathogenesis of Cryptococcus neoformans infection. Eukaryot Cell. 2007;6(8):1486-96.

72. Chang $Y$, Jong A, Huang S, Zerfas P, Kwon-Chung K. CPS1, a homolog of the Streptococcus pneumoniae type 3 polysaccharide synthase gene, is important for the pathobiology of Cryptococcus neoformans. Infect Immun. 2006;74(7):3930-8

\section{Submit your next manuscript to BioMed Central and we will help you at every step:}

- We accept pre-submission inquiries

- Our selector tool helps you to find the most relevant journal

- We provide round the clock customer support

- Convenient online submission

- Thorough peer review

- Inclusion in PubMed and all major indexing services

- Maximum visibility for your research

Submit your manuscript at www.biomedcentral.com/submit 